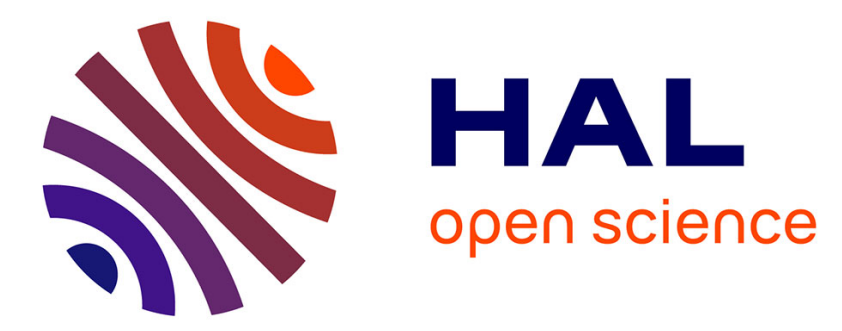

\title{
Kinetic modeling of polypropylene thermal oxidation during its processing by rotational molding
}

\author{
Salah Sarrabi, Xavier Colin, Abbas Tcharkhtchi
}

\section{To cite this version:}

Salah Sarrabi, Xavier Colin, Abbas Tcharkhtchi. Kinetic modeling of polypropylene thermal oxidation during its processing by rotational molding. Journal of Applied Polymer Science, 2010, 118 (2), pp.980996. 10.1002/app.32459. hal-02269250

\section{HAL Id: hal-02269250 \\ https://hal.science/hal-02269250}

Submitted on 22 Aug 2019

HAL is a multi-disciplinary open access archive for the deposit and dissemination of scientific research documents, whether they are published or not. The documents may come from teaching and research institutions in France or abroad, or from public or private research centers.
L'archive ouverte pluridisciplinaire HAL, est destinée au dépôt et à la diffusion de documents scientifiques de niveau recherche, publiés ou non, émanant des établissements d'enseignement et de recherche français ou étrangers, des laboratoires publics ou privés. 


\title{
Kinetic Modeling of Polypropylene Thermal Oxidation During Its Processing by Rotational Molding
}

\author{
S. Sarrabi, X. Colin, A. Tcharkhtchi \\ Laboratoire d'Ingénierie des Matériaux (UMR-CNRS 8006), Arts et Métiers ParisTech, 151 Boulevard de l'Hôpital, \\ Paris 75013, France
}

\begin{abstract}
The main drawback of rotational molding is a long stay (several dozens of minutes) of polymer in melt state at high temperature in atmospheric air. To prevent any significant polymer thermal degradation, it is necessary to define, preliminary, a processing window in a temperature-molar mass map. The objective of this article is to elaborate and check the validity of a general thermal degradation model devoted to determine, in a near future, some important boundaries of this processing window. This model is composed of two distinct levels: (i) The first level is derived from the thermal transfer mechanisms occurring during a processing operation, polymer phase changes (i.e., melting and crystallization) being simulated by the enthalpy method; and (ii) The second
\end{abstract}

level is derived from the oxidation mechanistic scheme of free additive polymer in melt state established in a previous study, but completed, here, by adding the main stabilization reactions of a common synergistic blend of antioxidants, widely used for rotational molding polymer grades. By juxtaposing such "thermal" and "chemical" levels, it is possible to predict the polymer thermal degradation during a whole processing operation. The validity of both levels is successfully checked in real rotational molding conditions for polypropylene (PP). (c) 2010 Wiley Periodicals, Inc. J Appl Polym Sci 118: 980-996, 2010

Key words: rotational molding; kinetic modeling; enthalpy method; thermal degradation; polypropylene stabilization

\section{INTRODUCTION}

Rotational molding is a relatively old processing technique for the production of cheap hollow parts made of thermoplastic polymers. As an example, the first patent describing a rotational molding machine, relatively close to those currently used in production today, was registered in $1935 .{ }^{1}$ As shown in Figure 1, its principle is relatively simple. ${ }^{2}$ Until a relatively recent date, it was considered as a marginal processing technique, compared with more conventional ones, such as injection molding, extrusion, extrusion blowing, because it was used only for the production of pieces mechanically little solicited, for instance, toys or floats.

In the 1980's, however, convinced by the promises of this technique, the Prof. Crawford initiated the first research activities on rotational molding in Europe at the Queen's University of Belfast. ${ }^{3}$ In the beginning of the 2000's, in France, many research works started under the impulse of the French Atomic Agency (CEA LE RIPAULT). ${ }^{4}$ The main objectives were to better understand and optimize the different processing stages to guarantee, in a near future, the reproducibility of the piece quality. Listed by a chronological

Correspondence to: S. Sarrabi (sssarabi@gmx.com). order, the critical stages during a processing operation by rotational molding are:

- Melting and sintering of polymer particles ${ }^{5}$;

- Homogenization of molten polymer ;

- Reduction in porosity ${ }^{6,7}$;

- Solidification and crystallization. ${ }^{8}$

To facilitate the study of these various stages, some research teams developed specific laboratory equipments, such as heating plates, which can be placed under the objectives of an optical microscope $^{9}$ or especially adapted control instruments, such as the ROTOLOG system, allowing the measurement of the local temperature in any place of the polymer piece or the wall mold during a processing operation..$^{10}$ Some of these stages are far from being totally elucidated yet and their studies are in progress at the laboratory. ${ }^{11,12}$

The recent developments made on the rotational molding machines allow, now, to consider the production of economically attractive technical pieces satisfying the requirements of many sectors, very demanding on the piece quality, such as automotive, civil engineering, or even sport and leisure. ${ }^{13}$ In some cases of figure, rotational molding became an interesting alternative to extrusion blowing. ${ }^{14}$

The main drawback of rotational molding, comparatively to conventional processing techniques (injection molding, extrusion, extrusion blowing, 


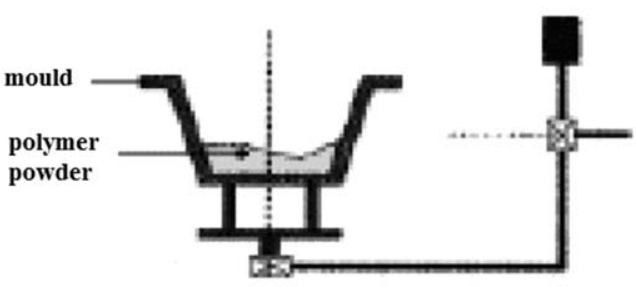

1) Loading

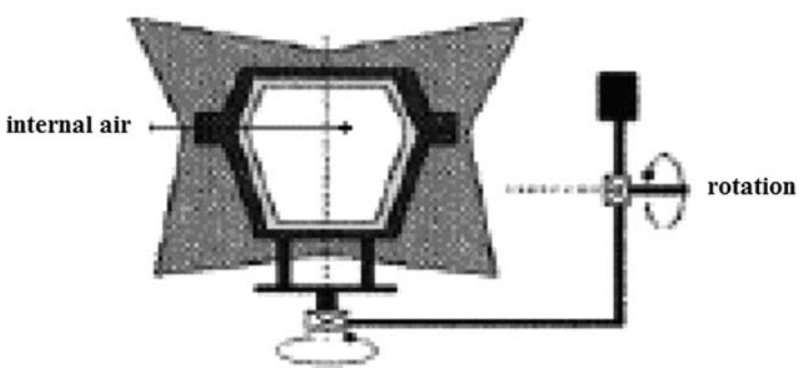

3) Cooling

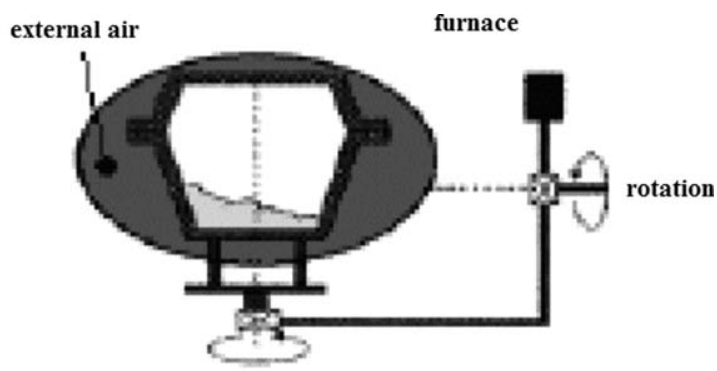

2) Heating

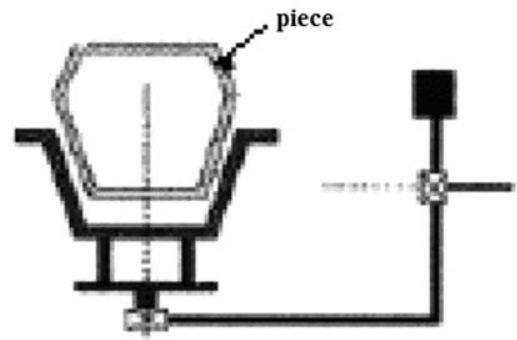

4) Demoulding

Figure 1 Principle of working of rotational molding.

etc...), is a relatively long processing cycle. Indeed, the polymer is maintained in melt state at high temperature in atmospheric air during several dozens of minutes. ${ }^{15}$ However, polymers are characterized by the existence of a relatively low thermal stability ceiling in the temperature-molar mass map. ${ }^{16}$ There are thus important risks of polymer thermal degradation, and the choice of an efficient system of stabilization, protecting the polymer during a whole processing operation, appears as crucial for rotational molding. Let us recall that some common thermoplastic polymers, for instance polyoxymethylene (POM), polypropylene (PP) and poly(vinyl chloride) (PVC), display a so low thermal stability ceiling that they could not be processed without the use of thermal stabilizers. ${ }^{17}$ As an example, in the absence of antioxidants (and any other reactive adjuvant), the oxidation induction time of PP is about 31 sec at $200^{\circ} \mathrm{C}, 15 \mathrm{~min}$ at $150^{\circ} \mathrm{C}$ and $19 \mathrm{~h}$ at $100^{\circ} \mathrm{C}$ in atmospheric air. ${ }^{18}$ These values are largely lower (from 6 to 7 times lower) than those reported for another polyolefin, deemed more stable thermally: the polyethylene (PE). ${ }^{19}$ Moreover, another interesting specificity of $\mathrm{PP}$ is that this polymer presents a relatively high critical molar mass, $M_{F} \approx 200 \mathrm{~kg}$ $\mathrm{mol}^{-1}$, separating the ductile behavior (rupture after plastic deformation when $M>M_{F}$ ) from the brittle behavior (rupture in the absence of plastic deformation when $\left.M<M_{F}\right){ }^{20}$ Thus, PP embrittlement occurs at a very low conversion ratio of the oxidative chain scission process, practically undetectable by the common physico-chemical laboratory techniques, such as FTIR or NMR spectrometry.

PP thermal degradation was intensively studied in half past century, but essentially in solid state, i.e., typically between 40 and $150^{\circ} \mathrm{C} .^{21-24}$ In this temperature range, oxidation mechanism is now relatively well elucidated: it is a radical chain reaction initiated by its main propagation product: the hydroperoxide group. ${ }^{25}$ Nonempirical kinetic models, derived from this "closed-loop" mechanism, were checked successfully in wide temperature and partial oxygen pressure ranges. ${ }^{26,27}$ On one hand, these models confirm that the sharp auto-acceleration of oxidation, at the end of the induction period, is the direct consequence of the "closed-loop" character. On the other hand, they show that the relative thermal instability of PP, comparatively to $\mathrm{PE}$, results from the combination of two factors:

i. The presence of a hydrogen atom $(\mathrm{H})$ more labile in the monomer unit. Indeed, the dissociation energy of a $\mathrm{CH}$ bond in a methyne group is about $376-380 \mathrm{~kJ} \mathrm{~mol}^{-1}$, against $393 \mathrm{~kJ}$ $\mathrm{mol}^{-1}$ in a methylene group

ii. A lower reactivity of peroxyl radicals $\left(\mathrm{PO}_{2}^{\bullet}\right)$. Indeed, it is well known that their reactivity classifies as follows:

Tertiary radicals $\gg$ Secondary radicals $>$ Primary radicals. ${ }^{28}$ 
Curiously, there are too few papers devoted to PP thermal degradation in melt state, despite the relative simplicity of the material structure under study (no crystallinity) and the increasing craze, in the last two decades, for studies on polymer thermal degradation during processing ${ }^{29-32}$ or mechanical recycling. ${ }^{33-35}$ In a very recent study, we have proposed an oxidation mechanistic scheme for free additive PP in melt state. ${ }^{36}$ This scheme presents the following characteristics:

- Below $250^{\circ} \mathrm{C}$, oxidation is mainly initiated by the thermal decomposition of hydroperoxide groups. Indeed, attempts made to introduce other sources of radicals [e.g., the thermal decomposition of structural irregularities, polymer thermolysis, or even, the direct attack of polymer by oxygen (which is a biradical in ground state)] in the mechanistic scheme were unsuccessful. Even if the existence of intrinsic sources of radicals cannot be totally excluded, their contribution to initiation is clearly negligible in this case of figure.

- The bimolecular termination of peroxyl radicals is not very efficient. The vast majority of radicals' pairs (about $90 \%$ between 190 and $230^{\circ} \mathrm{C}$ ) escape from the cage. As a result, a non terminating bimolecular termination of peroxyl radicals has been introduced in the mechanistic scheme.

- Oxidation leads to a large amount of volatile products, well before the end of the induction period. The main volatile compounds were detected in real time by a very sensitive technique, coupling proton transfer reaction, Fourier transform ion cyclotron resonance and mass spectrometry, developed in France at the Orsay University by the Alyxan Company. ${ }^{37}$ Listed by order of importance, they are: acetone, acetaldehyde, formaldehyde and methyl acrolein. Below $250^{\circ} \mathrm{C}$, in atmospheric air, acetone is the main volatile compound, as observed by other authors. ${ }^{24,38,39} \mathrm{As}$ an example, at $230^{\circ} \mathrm{C}$, it represents more than $55 \%$ in moles of the total amount of detected gasses. ${ }^{36}$ Thus, in a first approximation, only the formation of acetone was considered and detailed in the mechanistic scheme.

- Oxidation leads to the build-up of degradation products in the material. The more interesting ones, from a practical point of view, because they are easily accessible by common laboratory techniques, for instance by FTIR spectrophotometry, are the carbonyl (at about 1713-1722 $\mathrm{cm}^{-1}$ ) and hydroxyl species (at about $3378-3553 \mathrm{~cm}^{-1}$ ). The formation of both products was considered and detailed in the mechanistic scheme.

Then, we have derived a non empirical kinetic model from this mechanistic scheme, to simulate the

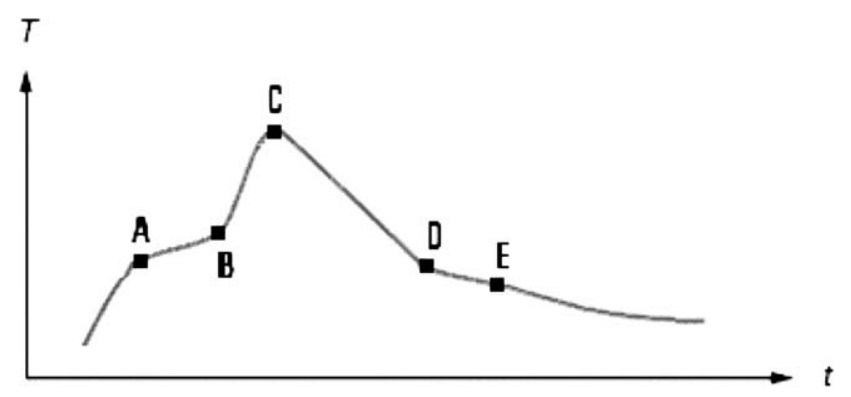

Figure 2 Typical rotational molding thermogram. Points $\mathrm{A}$ and $\mathrm{B}$ correspond respectively to the beginning and end of polymer melting. Point $C$ corresponds to the end of heating stage or beginning of cooling stage. Points D and E correspond respectively to the beginning and end of polymer crystallization.

kinetic curves of oxidation products build-up and mass changes for free additive PP at high temperature in melt state. ${ }^{36}$ This "chemical" model predicts satisfyingly the experimental results of isothermal aging tests performed between 170 and $250^{\circ} \mathrm{C}$ in airventiled ovens.

Despite this apparent success, this "chemical" model must be improved for, at least, two reasons:

- Industrial polymers are rarely used pure. In general, they contain many additives (lubricants, plasticizers, antioxidants, etc...) and even, sometimes, mineral fillers. The introduction of the main stabilization reactions of the common synergistic blends of antioxidants in the mechanistic scheme would allow, in a first step, to extend the "chemical" model to the vast majority of rotational molding PP grades.

- A rotational molding machine is far from being an ideal thermal reactor. Indeed, the temperature is not isothermal and homogeneous. An example of typical rotational molding thermogram recorded by a thermocouple inserted at a certain depth $\mathrm{z}$ in a polymer piece: $\mathrm{T}(\mathrm{z}, \mathrm{t})$, or in the center of the mold: $\mathrm{T}_{\mathrm{a}}(\mathrm{t})$, is given in Figure 2. It can be decomposed into two distinct stages: a heating stage followed by a cooling stage. Moreover, both stages do not occur with a constant rate, since they display, each one, a pseudo-plateau resulting from a polymer phase change (melting and crystallization respectively).

At least, a polymer being a thermal insulator, temperature gradients develop in the piece thickness.

The objective of the present article is to elaborate a general kinetic model for PP thermal degradation during its processing by rotational molding. This model will be the juxtaposing of two distinct levels: 


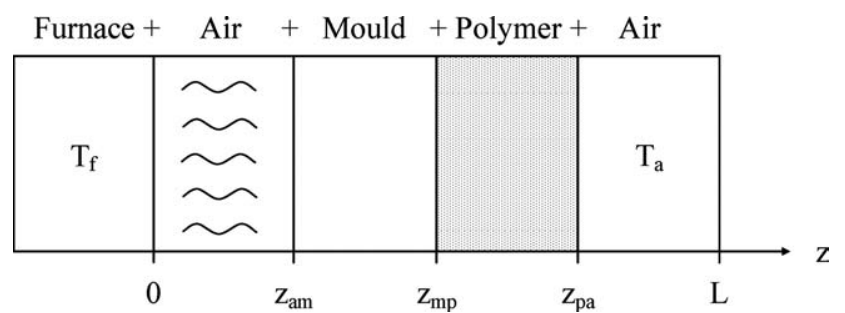

Figure 3 Simplified scheme of a rotational molding machine. Main parameters are: $T_{f}=$ furnace temperature; $z=0=$ outer furnace surface; $z_{\mathrm{am}}=$ outer mold surface; $z_{\mathrm{mp}}=$ mold $/$ polymer interface; $z_{\mathrm{pa}}=$ polymer/internal air interface; $z=\mathrm{L}=$ center of the mold; $T_{a}=$ internal air temperature.

i) A first level describing the polymer thermal history during a whole processing operation. It will simulate the local temperature changes against processing time in any place $\mathrm{z}$ of the polymer piece: $T(z, t)$, knowing two temperature boundaries: the furnace temperature $T_{f}$ and the internal air temperature (in the center of the mold) $\mathrm{T}_{\mathrm{a}}(\mathrm{t})$, and the thermal characteristics of the different elements (furnace, materials, fluids, gas, etc...) constituting the rotational molding machine.

ii) A second level predicting the local conversion ratio of PP thermal degradation knowing the local temperature changes. It will give access to very important physico-chemical properties, from a practical point of view, because they are easily accessible by common laboratory techniques, in particular: local antioxidants depletion, local build-up of oxidation products (in particular carbonyl species) and global mass changes.

The validity of such "thermal" and "chemical" levels will be tentatively checked in real rotational molding conditions.

\section{MODEL FOR THERMAL TRANSFER}

The aim of this first section is to recall the mechanisms of thermal transfer taking place during a processing operation by rotational molding and then, to derive from these mechanisms a non empirical kinetic model allowing to determine the local temperature changes against processing time in any place $\mathrm{z}$ of the polymer piece: $T(z, t)$, and in the center of the mold: $T_{a}(t)$.

\section{Basis equations}

Let's consider, in a first approximation, a spherical mold. In this case, a rotational molding machine can be simply schematized as indicated in Figure 3. The piece thickness is given by:

$$
e_{P}=z_{\mathrm{pa}}-z_{\mathrm{mp}}
$$

The thickness and inner diameter of the mold are respectively given by:

$$
\begin{gathered}
e_{m}=z_{\mathrm{mp}}-z_{\mathrm{am}} \\
\mathrm{d}_{\mathrm{m}}=2\left(\mathrm{~L}-\mathrm{z}_{\mathrm{mp}}\right)
\end{gathered}
$$

Thermal transfers take place across the different elements (furnace, external and internal air, mold, polymer piece) constituting the rotational molding machine, but also at the interfaces between these elements:

1) The furnace is the only heat source. It is maintained at a constant temperature value $T_{f}$ during the whole duration $t_{C}$ of the heating stage. Then, the mold is removed from the furnace and aircooled with a fan. It can be thus written:

$$
\begin{gathered}
T(z=0, t)=T_{f} \quad \text { when } 0 \leq t \leq t_{C} \\
T(z=0, t)=25^{\circ} \mathrm{C} \quad \text { when } \mathbf{t}>\mathbf{t}_{\mathrm{C}}
\end{gathered}
$$

2) The mold is not in contact with the furnace. It is separated from this latter by a distance $\mathrm{z}_{\mathrm{am}}$. Convection ensures the thermal transfer from the outer furnace surface to the outer mold surface, i.e. across the external air:

$$
-\left.k_{m} \frac{\partial T}{\partial z}\right|_{z_{a m}, t}=h_{e a}\left[T\left(z_{a m}, t\right)-T(0, t)\right]
$$

where $k_{m}$ is the mold thermal conductivity and $\mathrm{h}_{\mathrm{ea}}$ is the coefficient of external air convection.

3) Conduction ensures the thermal transfer across the mold:

$$
k_{m} \frac{\partial^{2} T}{\partial z^{2}}=\rho_{m} C_{m} \frac{\partial T}{\partial t}
$$

where $\rho_{\mathrm{m}}$ and $C_{m}$ are respectively the mold density and calorimetric capacity.

4) The continuity of thermal transfer between the outer and inner mold surfaces is given by:

$$
-k_{m} \times\left.\frac{\partial T}{\partial z}\right|_{z_{a m, t}}=-k_{p} \times\left.\frac{\partial T}{\partial z}\right|_{z_{m p}, t}
$$

where $k_{p}$ is the thermal conductivity of the solid (in this case, $\left.k_{P}=k_{\mathrm{SP}}\right)$ or liquid polymer $\left(k_{P}=k_{\mathrm{IP}}\right)$.

5) A non empirical equation for the thermal transfer across the polymer piece could be:

$$
(1-\varepsilon) \rho_{\mathrm{p}} \frac{\partial\left(\mathrm{C}_{\mathrm{p}} \mathrm{T}\right)}{\partial \mathrm{t}}+\Delta \mathrm{H}=\frac{\partial}{\partial \mathrm{z}}\left(\mathrm{k}_{\mathrm{p}} \frac{\partial \mathrm{T}}{\partial \mathrm{z}}\right)
$$


where $\varepsilon$ is the porosity in the polymer piece. It is, any doubt, the parameter that is the most difficult to control and determine during a processing operation. In a first approach, one can consider that the starting polymer powder is composed of spherical particles of same diameter. In this case, the porosity would be about $32 \%$ for a centered cubic stacking and about $26 \%$ for a centered faces cubic or a compact hexagonal stacking.

$\Delta \mathrm{H}$ is the heat for phase change of the polymer under study. It takes the following values:

- During the heating stage, at the melting point (when $T(\mathrm{z}, \mathrm{t})=T_{M}, T_{M}$ being the melting temperature): $\Delta H=+H_{M}$

- During the cooling stage, at the crystallization point (when $T(\mathrm{z}, \mathrm{t})=T_{C}, T_{C}$ being the crystallization temperature): $\Delta \mathrm{H}=-H_{C}$

- Elsewhere (when $\mathrm{T}(\mathrm{z}, \mathrm{t}) \neq T_{M}$ and $T_{C}$ ): $\Delta H$ $=0$.

$\rho_{p}$ and $C_{p}$ are respectively the polymer density and calorimetric capacity.

6) Convection ensures the thermal transfer from the inner surface of polymer piece to the center of the mold, i.e. across the internal air:

$$
-\left.k_{p} \frac{\partial T}{\partial z}\right|_{z_{p a}, t}=h_{i a}\left[T(z=L, t)-T\left(z_{p a}, t\right)\right]
$$

where $h_{\mathrm{ia}}$ is the coefficient of internal air convection.

7) Let's note that the problem under study presents a central symmetry in the center of the mold (i.e., at $z=L$ ), so that:

$$
\left.\frac{\partial \mathrm{T}}{\partial \mathrm{z}}\right|_{\mathrm{z}=\mathrm{L}, \mathrm{t}}=0
$$

The system of eq. (4-11) constitutes the "core" of the thermal transfer model. At this stage, the only unknown quantity is the heat of polymer phase change $\Delta \mathrm{H}$. Its mathematical expression against temperature and spatial position $\mathrm{z}$ in the polymer piece thickness will be determined in the following section.

\section{Heat of melting}

Since the beginning of 1990's, several models have been established on the basis of eq. (4-11) to simulate the temperature gradients appearing in the piece thickness during a processing operation by rotational molding. These models are distinguished by the more or less arbitrary choice of the mathematical expression of the melting heat $\mathrm{H}_{\mathrm{M}}$.

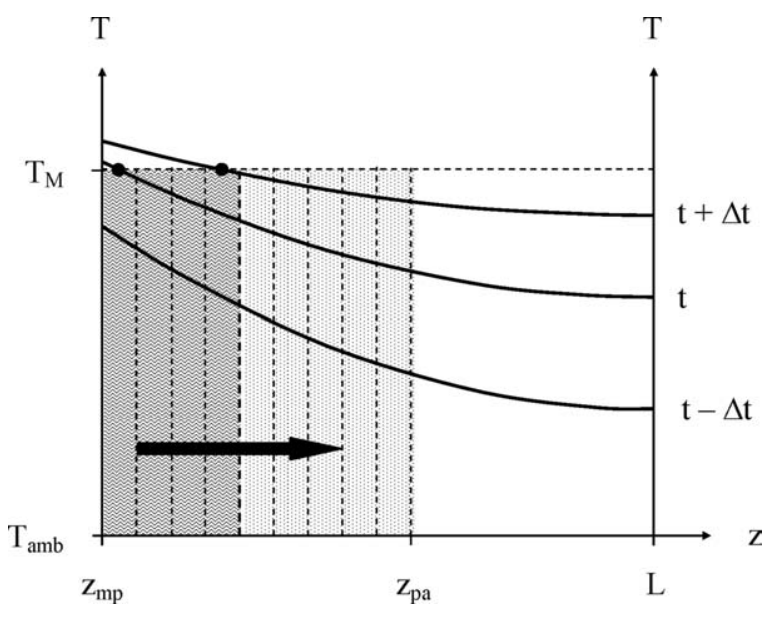

Figure 4 Schematization of the progressive melting of polymer powder, elementary layer by elementary layer, in a piece submitted to a temperature gradient $\mathrm{T}(\mathrm{z}, \mathrm{t})$. At $\mathrm{t}+$ $\Delta t$, the molten polymer is represented by a shaded area, whereas solid polymer is represented by a dotted area. The arrow indicates the direction of moving of the molten polymer front.

In the pioneering works of Sun and Crawford, ${ }^{40}$ the polymer powder is considered like a liquid. In other words, it is assumed that the solid/liquid transition occurs without any enthalpy change (i.e. $\mathrm{H}_{M}$ $=0)$. This is a non sense since it is well known that polymer melting is highly endothermic $\left(\mathrm{H}_{\mathrm{M}}<0\right)$. It is thus not surprising that the resulting kinetic model leads to serious inaccuracies and does not predict some important characteristics of the rotational molding thermograms, in particular the existence of a pseudo-plateau of melting [A $\rightarrow$ B] (Fig. 2). Despite that, this is the model the most widely used in industry. It is implemented in a commercial software named ROTOSIM. ${ }^{41}$

To tentatively give a physical meaning to this pseudo-plateau, let's discretize the polymer piece into $\mathrm{N}$ elementary layers of thickness $\mathrm{dz}$ (Fig. 4). Before the introduction of the mold in the furnace, the temperature is uniform in the whole piece thickness and equals to room temperature $\mathrm{T}_{\mathrm{amb}}$. As soon as the mold is introduced in the furnace, a temperature gradient $T(z, t)$ develops in the piece thickness as schematized in Figure 3. The melting of the polymer powder occurs progressively, elementary layer by elementary layer, whenever the local temperature $T(z, t)$ reaches the melting temperature $T_{M}$. It starts in the warmest layer (the outer superficial layer in contact with the mold) and finishes in the coldest one (the inner superficial layer in contact with the internal air). Since polymer melting is highly endothermic, the melting of each layer slows significantly the increase in temperature in the following sublayers. It is thus expected that the pseudo-plateau of melting is more pronounced if the thermocouple is 
inserted in deeper layers beneath the outer piece surface.

The endothermic character of melting was first taken into account by Gogos and al. ${ }^{42,43}$ These latter have proposed a two-phases kinetic model in which the molten polymer is separated from the polymer powder by an interface. The melting of the polymer powder occurs when the interface temperature $T_{\mathrm{i}}$ $(\mathrm{z}, \mathrm{t})$ reaches the melting temperature $T_{M}$. Unfortunately, the implementation of such a model is relatively heavy and complicated for, at least, two reasons:

i. On one hand, the liquid/solid interface must be represented by a sufficiently thin elementary layer To be able to describe satisfyingly the thermal and physical transitions at this interface, which implies the use of an adaptive meshing, extremely tight at the immediate vicinity of the interface and relatively slack elsewhere.

ii. On the other, the phase change of the polymer under study must be described by an additional equation at the interface. This is a balance equation expressing that the heat of phase change is equal to the difference between the heats crossing the solid polymer powder and the molten polymer by conduction.

Moreover, the model fails to account for the pseudo-plateau of melting. The main reason is that, in a particles based material, the melting temperature is not a constant value as in a bulk and homogeneous material. ${ }^{44}$ One can imagine several reasons (stacking defects of particles, presence of air in the interstices, thermal resistance of air/particle and particle/particle interfaces, etc...) to tentatively explain why the melting temperature increases gradually as the front of molten polymer moves into the piece.

The advantages of enthalpy method are twofold. ${ }^{45}$ This method does not need to use a solid/liquid interface and thus, to calculate specific boundary conditions at this interface. Moreover, it takes directly into account the local changes in melting temperature in a particles based material. Since it was abundantly detailed and successfully used in a previous publication, ${ }^{46}$ it will be rapidly recalled here. Let's consider two successive elementary layers of polymer powder, noted (i) and $(i+1)$, of which the corresponding melting temperatures classify in the following order: $\mathrm{T}_{\mathrm{Mi}}<\mathrm{T}_{\mathrm{Mi}+1}$ (Fig. 5). The global enthalpy changes with temperature: $H=f(T)$, can be decomposed into three distinct linear parts:

1) In domain (1), the temperature is lower than the melting temperature $\mathrm{T}_{\mathrm{Mi}}$ :

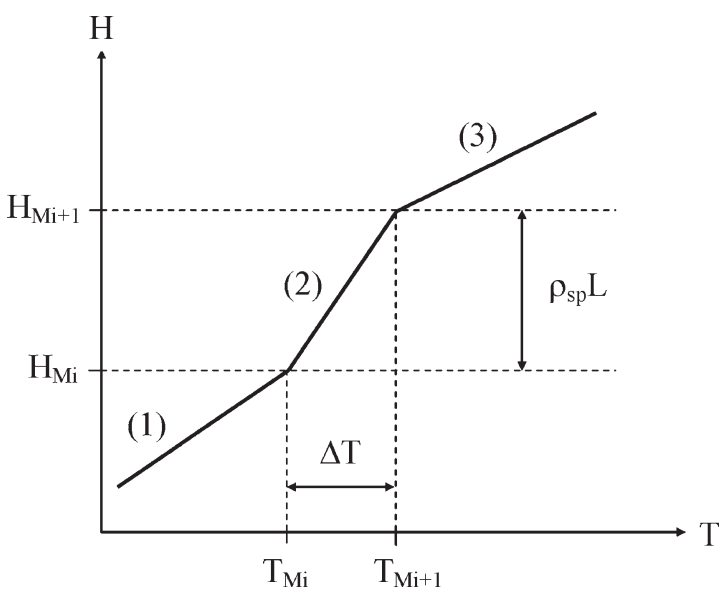

Figure 5 Law of global enthalpy changes with temperature. Main parameters are: $T_{\mathrm{Mi}}=$ melting temperature of elementary layer (i); $T_{\mathrm{Mi}+1}=$ melting temperature of elementary layer $(i+1) ; L=$ latent heat of melting; and $\rho_{\mathrm{sp}}$ $=$ solid polymer density.

$$
H=\rho_{s p} C_{s p}\left(T-T_{0}\right)+H_{0}
$$

where $\rho_{\mathrm{sp}}$ and $\mathrm{C}_{\mathrm{sp}}$ are respectively the density and calorimetric capacity of the solid polymer. $\mathrm{H}_{0}$ is the reference heat value at the reference temperature $\left(T=T_{0}=298 \mathrm{~K}\right)$.

2) In domain (2), the temperature is situated between the melting temperatures $T_{\mathrm{Mi}}$ and $T_{\mathrm{Mi}+1}$, only the layer (i) is melted:

$$
H=\frac{\rho_{s p} L}{\Delta T}\left(T-T_{M i}\right)+H_{M i}
$$

where $\Delta T=T_{\mathrm{Mi}}-T_{\mathrm{Mi}+1}$ and $\mathrm{L}$ is the latent heat of melting.

3) In domain (3), the temperature exceeds the melting temperature $T_{\mathrm{Mi}+1}$, both layers are melted:

$$
H=\rho_{l p} C_{l p}\left(T-T_{\mathrm{Mi}+1}\right)+H_{\mathrm{Mi}+1}
$$

where $\rho_{\mathrm{lp}}$ and $C_{\mathrm{lp}}$ are respectively the density and calorimetric capacity of the molten polymer.

Finally, in the present study, the enthalpy method was selected to describe all polymer phase changes, i.e. both the pseudo-plateaus of melting $[\mathrm{A} \rightarrow \mathrm{B}]$ and crystallization $[\mathrm{D} \rightarrow \mathrm{E}]$.

\section{Numerical programming and solving}

Finally, the "thermal" kinetic model, composed of eq. (4-14), was selected for the present study. It was programmed and solved numerically in a 
commercial software environment: Matlab, to predict the local temperature changes against processing time, in any place $\mathrm{z}$ of the polymer piece: $T(\mathrm{z}, \mathrm{t})$, and in the center of the mold: $T_{a}(t)$.

The "core" of the model was rewritten in finite differences using a centered implicit scheme for space (z) and a decentred implicit scheme for time (t). It was then integrated using an implicit Euler algorithm of order 1 .

\section{MODEL FOR CHEMICAL DEGRADATION}

The aim of this second section is to recall the mechanisms of thermal degradation for rational molding PP grades at high temperature in melt state and then, to derive from these mechanisms a non empirical kinetic model allowing to determine the local structural changes against time of exposure.

\section{Mechanistic scheme}

Since the oxidation mechanistic scheme of free additive PP in melt state has been largely detailed in a previous publication, ${ }^{36}$ it will be rapidly recalled below. It is composed of 9 elementary reactions:

(1u) $\mathrm{POOH} \longrightarrow 2 \mathrm{P}^{\bullet}+\left(1-\gamma_{1}\right) \mathrm{P}-\mathrm{OH}$

$$
+\gamma_{1} \mathrm{P}=\mathrm{O}+\mathrm{H}_{2} \mathrm{O}+v \mathrm{~V} \quad(-2 \mathrm{PH}) \quad\left(\mathrm{k}_{1 \mathrm{u}}\right)
$$

(1b) $2 \mathrm{POOH} \longrightarrow \mathrm{P}^{\bullet}+\mathrm{PO}_{2}^{\bullet}+\left(1-\gamma_{1}\right) \mathrm{P}-\mathrm{OH}$

$$
+\gamma_{1} \mathrm{P}=\mathrm{O}+\mathrm{H}_{2} \mathrm{O}+v \mathrm{~V} \quad(-\mathrm{PH}) \quad\left(\mathrm{k}_{1 \mathrm{~b}}\right)
$$

(2) $\mathrm{P}^{\bullet}+\mathrm{O}_{2} \longrightarrow \mathrm{PO}_{2}^{\bullet} \quad\left(\mathrm{k}_{2}\right)$

(3) $\mathrm{PO}_{2}^{\bullet}+\mathrm{PH} \longrightarrow \mathrm{POOH}+\mathrm{P}^{\bullet} \quad\left(\mathrm{k}_{3}\right)$

(4) $\mathrm{P}^{\bullet}+\mathrm{P}^{\bullet} \longrightarrow \gamma_{4} \mathrm{P}-\mathrm{P}+\left(1-\gamma_{4}\right) \mathrm{PH}+\left(1-\gamma_{4}\right) \mathrm{F}$

(5) $\mathrm{P}^{\bullet}+\mathrm{PO}_{2}^{\bullet} \longrightarrow \gamma_{5} \mathrm{POOP}+\left(1-\gamma_{5}\right) \mathrm{POOH}$

$$
+\left(1-\gamma_{5}\right) \mathrm{F}
$$

(60) $\mathrm{PO}_{2}^{\bullet}+\mathrm{PO}_{2}^{\bullet} \longrightarrow\left[\mathrm{PO}^{\bullet} \cdot \mathrm{OP}_{\text {cage }}+\mathrm{O}_{2} \quad\left(\mathrm{k}_{60}\right)\right.$

(61) $\left[\mathrm{PO} \bullet{ }^{\bullet} \mathrm{OP}\right]_{\text {cage }} \longrightarrow$ POOP $\left(\mathrm{k}_{61}\right)$

(63) $\left[\mathrm{PO} \bullet^{\bullet} \mathrm{OP}\right]_{\text {cage }} \longrightarrow 2 \mathrm{P}^{\bullet}+2 \gamma_{1} \mathrm{P}=\mathrm{O}$

$$
+2\left(1-\gamma_{1}\right) \mathrm{P}-\mathrm{OH}+2 \mathrm{vV} \quad(-2 \mathrm{PH}) \quad\left(\mathrm{k}_{63}\right)
$$

In this scheme, $\mathrm{P}-\mathrm{OH}$ and $\mathrm{P}=\mathrm{O}$ are the main inactive oxidation products: they are hydroxyl and ketone groups respectively.
$\mathrm{V}$ is the main volatile product, voluntary distinguished from water, formed by the (rapid) $\beta$ scission of alkoxy radicals $\left(\mathrm{PO}^{\bullet}\right)$. Let's recall that, in the temperature range under study (typically between 190 and $250^{\circ} \mathrm{C}$ ), in atmospheric air, acetone is the main volatile compound for PP. ${ }^{37}$ It is formed with a yield $v$ in the concerned elementary reactions and is characterized by a molar mass: $M_{V}=58 \mathrm{~g} \mathrm{~mol}^{-1}$.

F represents double bonds.

$\gamma_{1}, \gamma_{4}$ and $\gamma_{5}$ are the respective yields of ketone groups $(\mathrm{P}=\mathrm{O})$, alkyl-alkyl bridges $(\mathrm{P}-\mathrm{P})$ and peroxide bridges (POOP) in the concerned elementary reactions.

$k_{\mathrm{i}}$ are the rate constants of the different elementary reactions. In a given polymer physical state, they obey really to an Arrhenius law:

$$
k_{i}=k_{\mathrm{i} 0} \exp \left(-\frac{E_{i}}{R T}\right)
$$

where $k_{\mathrm{i} 0}$ and $E_{\mathrm{i}}$ are respectively the corresponding pre-exponential factor and activation energy.

The peculiarity of this oxidation mechanistic scheme is to generate its own initiator: the hydroperoxide group. This "closed-loop" character is responsible from the sharp auto-acceleration of oxidation process at the end of the induction period. ${ }^{25}$

Such a mechanistic scheme describes satisfyingly the general trends of thermal oxidation kinetics of free additive PP in melt state in a large temperature range (typically between 170 and $250^{\circ} \mathrm{C}$ ). ${ }^{36}$ It can be now extended to rotational molding PP grades.

There are two main families of "thermal" antioxidants, widely used for rotational molding PP grades, which were the subject of an abundant literature since the beginning of 1960 's. ${ }^{47-50}$ They are complementary antioxidant families because they act at two distinct stages of the "closed-loop" mechanism.

i. "Preventive" antioxidants reduce significantly the initiation rate (i.e. the rates of reactions $(1 \mathrm{u})$ and 1b)). They are thus used to prevent the oxidation start. The most current ones decompose $\mathrm{POOH}$ groups by a non radical way. In polyolefins, they are, in general, organic sulfides of thio-di-propionate type (DLTDP or DSTDP) or organic phosphites. The latter are reputed efficient at high temperature in processing conditions (typically when $\mathrm{T}>200^{\circ} \mathrm{C}$ ), whereas the former are rather efficient at low temperature (typically at ambient temperature) at long term in used conditions. ${ }^{50}$ In a first approximation, the action mechanism of this antioxidant family can be written ${ }^{48-50}$ :

$$
\text { (71) } \mathrm{POOH}+\mathrm{Dec} \longrightarrow \text { inactive products }
$$

where Dec is a "preventive" antioxidant of organic sulfide or phosphite type. 
ii) "Radical chain terminator" antioxidants increase the termination rate (and thus, reduce significantly the rate of propagation (3)). If we leave aside, for the moment, the free radicals (of nitroxy type) especially used as "photo-" or "radio-chemical" antioxidants, the most current "terminator" antioxidants are hydrogen donors. They are hindered phenols or secondary aromatic amines. Both antioxidant types are particularly efficient at low temperature (typically at ambient temperature) at long term in use conditions. ${ }^{50}$ Since they contain one (or several) very labile hydrogen atom(s), more labile than those belonging to any polymer substrate (PH), they will be noted $\mathrm{AH}$ in the following. As an example, the dissociation energy of the A-H bond is around 335$355 \mathrm{~kJ} \mathrm{~mol}^{-1}$ for hindered phenols, ${ }^{51-54}$ whereas the dissociation energy of the $\mathrm{P}-\mathrm{H}$ bond is around 375$395 \mathrm{~kJ} \mathrm{~mol}^{-1}$ for polyolefins. Thus, this antioxidant family will give easily a hydrogen atom to a peroxyl radical $\mathrm{PO}_{2}^{\circ}$. In a first approximation, its action mechanism can be written ${ }^{48-50}$ :

$$
\text { (72) } \mathrm{PO}_{2}^{\bullet}+\mathrm{AH} \longrightarrow \mathrm{POOH}+\mathrm{A}^{\bullet}\left(\mathrm{k}_{72}\right)
$$

where $\mathrm{AH}$ is a "terminator" antioxidant of hindered phenol or secondary aromatic amine type.

Let's note that the $\mathrm{A}^{\bullet}$ radical thus formed, as well as the $\mathrm{B}^{\bullet}$ radical formed by (rapid) isomerisation of radical $\mathrm{A}^{\bullet}$ (in the case of hindered phenols), is not very reactive. One can thus consider, in first approach, that it is a stable species, unable to initiate new oxidation chains, even if, sometimes, the reality can be significantly more complicated..$^{55,56}$

Both "thermal" antioxidant families are rarely used alone. Synergistic effects between "preventive" and "terminator" antioxidants are well known since a long time in polyolefins and elastomers. ${ }^{57-59}$ For a long time, these effects were interpreted in terms of chemical interactions between antioxidants and/or their by-products, for instance:

- the phenol is regenerated by the reaction between the sulfide and the reaction products of phenol ${ }^{60}$;

- or simpler, the sulfide decomposes the hydroperoxide resulting from a stabilization step. $^{61}$

But, in a recent kinetic analysis study, it was shown that these synergistic effects could result from the fact that both antioxidant families act at two distinct stages of the "closed-loop" mechanism. In other words, they would be simple kinetic effects. ${ }^{62}$

Finally, the mechanistic scheme composed of 11 elementary reactions $\{1 \mathrm{u}, 1 \mathrm{~b}, 2,3,4,5,60,61,63,71$ and 72$\}$ has been selected for the present study.

\section{Basis equations}

The following system of differential equations can be derived from the previous oxidation mechanistic scheme:

$$
\begin{aligned}
& \frac{\mathrm{d}\left[\mathrm{P}^{\bullet}\right]}{\mathrm{dt}}=2 \mathrm{k}_{1 u} f_{\mathrm{PH}}[\mathrm{POOH}]+\mathrm{k}_{1 b} f_{\mathrm{PH}}[\mathrm{POOH}]^{2}-\mathrm{k}_{2}\left[\mathrm{P}^{\bullet}\right]\left[\mathrm{O}_{2}\right] \\
& +\mathrm{k}_{3}\left[\mathrm{PO}_{2}^{\bullet}\right][\mathrm{PH}]-2 \mathrm{k}_{4}\left[\mathrm{P}^{\bullet}\right]^{2}-\mathrm{k}_{5}\left[\mathrm{P}^{\bullet}\right]\left[\mathrm{PO}_{2}^{\bullet}\right] \\
& +2 \mathrm{k}_{63} f_{\mathrm{PH}}\left[\mathrm{PO}^{\bullet}{ }^{\bullet} \mathrm{OP}{ }^{\bullet}\right] \\
& \frac{\mathrm{d}\left[\mathrm{PO}_{2}^{\bullet}\right]}{\mathrm{dt}}=\mathrm{k}_{1 \mathrm{~b} f_{\mathrm{PH}}}[\mathrm{POOH}]^{2}+\mathrm{k}_{2}\left[\mathrm{P}^{\bullet}\right]\left[\mathrm{O}_{2}\right]-\mathrm{k}_{3}\left[\mathrm{PO}_{2}^{\bullet}\right][\mathrm{PH}] \\
& -\mathrm{k}_{5}\left[\mathrm{P}^{\bullet}\right]\left[\mathrm{PO}_{2}^{\bullet}\right]-2 \mathrm{k}_{60}\left[\mathrm{PO}_{2}^{\bullet}\right]^{2}-n_{\mathrm{AH}} \mathrm{k}_{72}[\mathrm{AH}]\left[\mathrm{PO}_{2}^{\bullet}\right] \\
& \frac{\mathrm{d}[\mathrm{POOH}]}{\mathrm{dt}}=-\mathrm{k}_{1 \mathrm{u}} f_{\mathrm{PH}}[\mathrm{POOH}]-2 k_{1 b} f_{P H}[\mathrm{POOH}]^{2} \\
& +\mathrm{k}_{3}\left[\mathrm{PO}_{2}^{*}\right][\mathrm{PH}]+\left(1-\gamma_{5}\right) \mathrm{k}_{5}\left[\mathrm{P}^{\bullet}\right]\left[\mathrm{PO}_{2}^{\bullet}\right]-\mathrm{k}_{71}[\mathrm{POOH}][\mathrm{Dec}] \\
& +\mathrm{n}_{\mathrm{AH}} \mathrm{k}_{72}\left[\mathrm{PO}_{2}^{*}\right][\mathrm{AH}] \\
& \frac{\mathrm{d}[\mathrm{PO} \bullet \mathrm{OP}]}{\mathrm{dt}}=\mathrm{k}_{60}\left[\mathrm{PO}_{2}^{*}\right]^{2}-\left(\mathrm{k}_{61}+\mathrm{k}_{63} \mathrm{f}_{\mathrm{PH}}\right)[\mathrm{PO} \bullet \cdot \mathrm{OP}]
\end{aligned}
$$

$$
\begin{array}{r}
\frac{\mathrm{d}[\mathrm{PH}]}{\mathrm{dt}}=-\left(2+\mathrm{n}_{\mathrm{PH}} \mathrm{v}\right) \mathrm{k}_{1 \mathrm{u}} f_{\mathrm{PH}}[\mathrm{POOH}] \\
-\left(1+\mathrm{n}_{\mathrm{PH}} \mathrm{v}\right) \mathrm{k}_{1 \mathrm{~b}} f_{\mathrm{PH}}[\mathrm{POOH}]^{2}-\mathrm{k}_{3}\left[\mathrm{PO}_{2}^{\bullet}\right][\mathrm{PH}] \\
+\left(1-\gamma_{4}\right) \mathrm{k}_{4}\left[\mathrm{P}^{\bullet}\right]^{2}-2\left(1+\mathrm{n}_{\mathrm{PH}}\right) \mathrm{k}_{63} f_{\mathrm{PH}}[\mathrm{PO} \bullet \bullet \mathrm{OP}] \\
\frac{\partial\left[\mathrm{O}_{2}\right]}{\partial \mathrm{t}}=\mathrm{D}_{\mathrm{O}_{2}} \frac{\partial^{2}\left[\mathrm{O}_{2}\right]}{\partial \mathrm{z}^{2}}-\mathrm{k}_{2}\left[\mathrm{P}^{\bullet}\right]\left[\mathrm{O}_{2}\right]+\mathrm{k}_{60}\left[\mathrm{PO}_{2}^{\bullet}\right]^{2} \\
\begin{array}{r}
\frac{[\mathrm{Dec}]}{\partial \mathrm{t}}= \\
=\mathrm{D}_{\mathrm{Dec}} \frac{\partial^{2}[\mathrm{Dec}]}{\partial \mathrm{z}^{2}}-\mathrm{k}_{71}[\mathrm{POOH}][\mathrm{Dec}] \\
+\mathrm{n}_{\mathrm{AH}} \mathrm{k}_{72}\left[\mathrm{PO}_{2}^{\bullet}\right][\mathrm{AH}]
\end{array}
\end{array}
$$

$$
\frac{\partial[\mathrm{AH}]}{\partial \mathrm{t}}=\mathrm{D}_{\mathrm{AH}} \frac{\partial^{2}[\mathrm{AH}]}{\partial \mathrm{z}^{2}}-\mathrm{n}_{\mathrm{AH}} \mathrm{k}_{72}\left[\mathrm{PO}_{2}^{\bullet}\right][\mathrm{AH}]
$$

In these equations:

$-D_{\mathrm{O}_{2}}, D_{\mathrm{Dec}}$ and $D_{\mathrm{AH}}$ are the respective coefficients of molecular species (oxygen, "preventive" and "terminator" antioxidants) diffusion. In a given polymer physical state, they obey really to an Arrhenius law:

$$
D_{i}=D_{i 0} \exp \left(-\frac{E_{i}}{R T}\right)
$$

where $D_{\mathrm{i} 0}$ and $E_{\mathrm{i}}$ are respectively the corresponding pre-exponential factor and activation energy. 
- $n_{\mathrm{AH}}$ is the functionality of the "terminator" antioxidant (number of active groups per antioxidant molecule);

$-n_{\mathrm{CO}}, n_{\mathrm{OH}}$ and $n_{\mathrm{PH}}$ are the respective numbers of ketone, hydroxyl and methyne groups in the average molecule of volatile compound. In the case of acetone: $n_{\mathrm{CO}}=1, n_{\mathrm{OH}}=0$, and $n_{\mathrm{PH}}=0$.

$-f_{\mathrm{PH}}$ is a mathematical function introduced in the system of differential equations to avoid that the substrate concentration becomes negative at high conversion ratios of the oxidation process. ${ }^{63}$ In a first approach, a hyperbolic mathematical form has been chosen to describe the changes of $f_{\mathrm{PH}}$ against $[\mathrm{PH}]$ :

$$
f_{\mathrm{PH}}=\frac{[\mathrm{PH}]}{[\mathrm{PH}]+\varepsilon}
$$

with, typically: $\varepsilon=10^{-2} \ll 1$. Let's note that the use of this function does not induce significant changes of the oxidation kinetics below a conversion value of about $99 \%$.

The system of eq. (16-23) constitutes the "core" of the "chemical" kinetic model. This system has been solved numerically, using the ODE23s Solver of the commercial software Matlab, recommended for the resolution of stiff problems of chemical kinetics. ${ }^{64}$ Boundary conditions were:

- In the whole polymer piece thickness (at any $\mathrm{z})$, when $t=0$ :

$$
\begin{gathered}
{\left[\mathrm{P}^{\bullet}\right]=\left[\mathrm{PO}_{2}^{\bullet}\right]=[\mathrm{PO} \bullet \mathrm{OP}]=0 \text { mol. } \mathrm{l}^{-1} ;} \\
{[\mathrm{POOH}]=[\mathrm{POOH}]_{0}=10^{-3}-10^{-2} \text { mol. }^{-1} ;} \\
{[\mathrm{PH}]=[\mathrm{PH}]_{0} \approx 20 \text { moll }^{-1}} \\
(\text { initial concentration of methyne groups) } \\
{\left[\mathrm{O}_{2}\right]=\left[\mathrm{O}_{2}\right]_{0}=\mathrm{P}_{\mathrm{O}_{2}} \times \mathrm{S}}
\end{gathered}
$$

(Henry law, ${ }^{65} \mathrm{P}_{\mathrm{O}_{2}}$ being the partial oxygen pressure in the aging atmosphere and $\mathrm{S}$ the coefficient of oxygen solubility into the polymer);

$[\mathrm{Dec}]=[\mathrm{Dec}]_{0}$ and $[\mathrm{AH}]=[\mathrm{AH}]_{0}$ (initial concentrations of antioxidants).

- At the polymer piece/internal air interface (at $z=z_{\mathrm{pa}}$ ), when $\mathrm{t}>0$ :

$\left[\mathrm{O}_{2}\right]=\left[\mathrm{O}_{2}\right]_{\mathrm{s}}=\mathrm{P}_{\mathrm{O}_{2}} \times \mathrm{S}$ (Henry's law, ${ }^{65}$ oxygen dissolution is instantaneous at the inner piece surface);

$$
\begin{aligned}
\mathrm{D}_{\text {Dec }} \frac{\partial^{2}[\mathrm{Dec}]}{\partial \mathrm{z}^{2}}=- & \beta_{\mathrm{Dec}}[\mathrm{Dec}] \text { and } \\
& \mathrm{D}_{\mathrm{AH}} \frac{\partial^{2}[\mathrm{AH}]}{\partial \mathrm{z}^{2}}=-\beta_{\mathrm{AH}}[\mathrm{AH}]
\end{aligned}
$$

(Billingham's law, ${ }^{22}$ antioxidants leave the inner piece surface (by evaporation) with a rate proportional to their concentration, $\beta_{\mathrm{Dec}}$ and $\beta_{\mathrm{AH}}$ being the respective coefficients of crossing the polymer/air interface by both types of antioxidants).

- At the polymer piece/mold interface (at $z=$ $\left.z_{\mathrm{mp}}\right)$, when $t>0$ :

Flows of molecular species (oxygen and antioxidants) $=0$ (i.e., the internal mold surface is impermeable to molecular species)

The numerical resolution of the "core" gives access to the spatial distribution (in the polymer piece thickness, along the $\mathrm{z}$ abscissa) of reactive products concentrations $\left(\left[\mathrm{P}^{\bullet}\right],\left[\mathrm{PO}_{2}^{*}\right],[\mathrm{POOH}],\left[\mathrm{PO}^{\bullet}\right.\right.$ $\left.{ }^{\circ} \mathrm{OP}\right]_{\text {cager }}[\mathrm{PH}],\left[\mathrm{O}_{2}\right],[\mathrm{Dec}]$ and $\left.[\mathrm{AH}]\right)$ and its evolution against time $(t)$.

\section{Physico-chemical properties}

From these concentrations, it was possible to calculate the local changes of two particularly important physico-chemical properties, because they can be easily checkable experimentally and thus, used to check the validity of the "core" of the "chemical" kinetic model.

They are:

- Concentration of ketone groups:

$$
\begin{aligned}
& \frac{\mathrm{d}[\mathrm{C}=\mathrm{O}]}{\mathrm{dt}}=\left(\gamma_{1}-\mathrm{n}_{\mathrm{CO}}\right) \mathrm{k}_{1 \mathrm{u}} f_{\mathrm{PH}}[\mathrm{POOH}] \\
& +\left(\gamma_{1}-\mathrm{n}_{\mathrm{CO}}\right) \mathrm{k}_{1 \mathrm{~b}} f_{\mathrm{PH}}[\mathrm{POOH}]^{2}+2\left(\gamma_{1}-\mathrm{n}_{\mathrm{CO}}\right) \\
& \mathrm{k}_{63} f_{\mathrm{PH}}[\mathrm{PO} \bullet \cdot \mathrm{OP}]
\end{aligned}
$$

— Mass changes:

$$
\frac{1}{m_{0}} \frac{\mathrm{dm}}{\mathrm{dt}}=-\frac{32}{\rho_{\mathrm{T}}} \frac{\mathrm{d}\left[\mathrm{O}_{2}\right]}{\mathrm{dt}}-\frac{18}{\rho_{\mathrm{T}}} \frac{\mathrm{d}\left[\mathrm{H}_{2} \mathrm{O}\right]}{\mathrm{dt}}-\frac{\mathrm{M}_{\mathrm{V}}}{\rho_{\mathrm{T}}} \frac{\mathrm{d}[\mathrm{V}]}{\mathrm{dt}}
$$

So that:

$$
\begin{array}{r}
\frac{1}{\mathrm{~m}_{0}} \frac{\mathrm{dm}}{\mathrm{dt}}=\frac{32}{\rho_{\mathrm{T}}}\left(\mathrm{k}_{2}\left[\mathrm{O}_{2}\right]\left[\mathrm{P}^{\bullet}\right]-\mathrm{k}_{60}\left[\mathrm{PO}_{2}^{\bullet}\right]^{2}\right) \\
-\frac{18}{\rho_{\mathrm{T}}}\left(\mathrm{k}_{1 \mathrm{u}} f_{\mathrm{PH}}[\mathrm{POOH}]+\mathrm{k}_{1 \mathrm{~b}} f_{\mathrm{PH}}[\mathrm{POOH}]^{2}\right) \\
-\frac{v \mathrm{M}_{\mathrm{V}}}{\rho_{\mathrm{T}}}\left(\mathrm{k}_{1 \mathrm{u}} f_{\mathrm{PH}}[\mathrm{POOH}]+\mathrm{k}_{1 \mathrm{~b}} f_{\mathrm{PH}}[\mathrm{POOH}]^{2}\right. \\
\left.+2 \mathrm{k}_{63} f_{\mathrm{PH}}[\mathrm{PO} \bullet \cdot \mathrm{OP}]\right)
\end{array}
$$


TABLE I

Main Characteristics of the Synergistic Blend of antioxidants

\begin{tabular}{llcc}
\hline Antioxidant & Property & Value & Unit \\
\hline Irgafos 168 & {$[\mathrm{Dec}]_{0}$} & $5.7 \times 10^{-3}$ & $\mathrm{~mol} \mathrm{~L}^{-1}$ \\
Irganox 1010 & {$[\mathrm{AH}]_{0}$} & $6.2 \times 10^{-3}$ & $\mathrm{~mol} \mathrm{~L}^{-1}$ \\
Irganox 1010 & $\mathrm{n}_{\mathrm{AH}}$ & 4 & - \\
\hline
\end{tabular}

$[\mathrm{Dec}]_{0}=$ initial concentration of Irgafos $168 ;[\mathrm{AH}]_{0}=$ initial concentration of Irganox 1010; $\mathrm{n}_{\mathrm{AH}}=$ number of reactive group per Irganox 1010 molecule.

In these equations:

$-M_{V}$ is the molar mass of the average volatile compound. In the case of acetone, $M_{V}=58 \mathrm{~g}$ $\mathrm{mol}^{-1}$

- $\rho_{T}$ is the density of molten PP, corresponding to the density of the amorphous phase at the temperature $\mathrm{T}$ under study. It was estimated from the density of the amorphous phase at ambient temperature $\left(\rho_{298} \mathrm{~K}=854 \mathrm{~g} \mathrm{~L}^{-166}\right)$ and the coefficient of cubic dilatation of the amorphous phase $\left(\alpha_{\mathrm{L}}=1.510^{-4} \mathrm{~K}^{-166}\right)$ :

$$
\rho_{\mathrm{T}}=\frac{\rho_{298 \mathrm{~K}}}{1+\alpha_{\mathrm{L}}(\mathrm{T}-298)}
$$

As an example, at $200^{\circ} \mathrm{C}$, the numerical application gives: $\rho_{473 \mathrm{~K}}=832 \mathrm{~g} \mathrm{~L}^{-1}$.

Eq. (28) and (30) were integrated numerically to determine the local changes of both physico-chemical properties and their evolution against time of exposure (i.e. $[\mathrm{P}=\mathrm{O}]$, and $\Delta m / m_{0}=\mathrm{f}(\mathrm{z}, \mathrm{t})$ ).

Finally, assuming that the polymer piece thickness does not vary much during exposure, the global changes of all the calculated quantities were determined by summing the contribution of each elementary layer:

$$
Y_{\text {glob }}(t)=\frac{1}{e_{p}} \int_{z_{m p}}^{z_{p a}} Y(z, t) d z
$$

where $\mathrm{Y}=\left[\mathrm{P}^{\bullet}\right],\left[\mathrm{PO}_{2}^{\bullet}\right],[\mathrm{POOH}],\left[\mathrm{PO}^{\bullet}{ }^{\bullet} \mathrm{OP}\right]_{\text {cage, }}[\mathrm{PH}]$, $\left[\mathrm{O}_{2}\right],[\mathrm{Dec}],[\mathrm{AH}],[\mathrm{P}=\mathrm{O}]$ or $\Delta m / m_{0}$.

Thus, the "chemical" kinetic model, composed of eq. (16-32), was selected for the present study.

\section{EXPERIMENTAL}

\section{Material}

The polymer under study is a rotational molding PP grade (melt flow index of $40 \mathrm{~g} / 10 \mathrm{~min}$ at $230^{\circ} \mathrm{C}$ under $2.16 \mathrm{~kg}$; density $\rho$ of $0.90 \mathrm{~g} . \mathrm{cm}^{-3}$ at $25^{\circ} \mathrm{C}$ ) provided by ICOPOLYMERS Company. It appears as a finely micronized powder. The average diameter of particles is approximately $100 \mu \mathrm{m}$.

This polymer powder is stabilized by a common synergistic blend of antioxidants developed and supplied by Ciba-Geigy. This latter is described as a particularly efficient blend both in processing conditions (typically when $\mathrm{T}>200^{\circ} \mathrm{C}$ ) and in used conditions (at ambient temperature) at long term. It is composed of an organic phosphite (Dec): Irgafos 168, and a hindered phenol (AH): Irganox 1010. The main characteristics of both antioxidants are reported in Table I.

Before processing, the as-received polymer powder was characterized by conventional laboratory techniques: Fourier transform infrared (FTIR) and ultraviolet (UV) spectrophotometries, differential scanning calorimetry (DSC) and steric exclusion chromatography (SEC). The main results are reported in Table II.

IR and UV spectrophotometries attest the presence of a synergistic blend of antioxidants in the polymer powder. Indeed, peaks characteristics of phosphite and phenols antioxidants are clearly observed at $850 \mathrm{~cm}^{-1}$ (stretching vibration of $\mathrm{P}-\mathrm{O}$ bond, in IR spectra) and $280 \mathrm{~nm}$ (in UV spectra) respectively.

The isotacticity ratio isoT was determined from the respective absorbances $\mathrm{A}_{998}$ and $\mathrm{A}_{973}$ of IR peaks located at 998 and $973 \mathrm{~cm}^{-1}$, using the classical equation $^{67,68}$ :

$$
\text { isoT }=100 \times\left[1-\frac{\mathrm{k}-1}{0.583 \mathrm{k}-0.113}\right]
$$

with: $k=\frac{\mathrm{A}_{973}}{\mathrm{~A}_{998}}$

The average thickness of crystalline lamella $\mathrm{L}_{\mathrm{C}}$ was estimated from the melting temperature $T_{M}$ using the classical Gibbs-Thomson equation:

\begin{tabular}{|c|c|c|c|}
\hline Property & Technique (conditions) & Value & Unity \\
\hline$M_{W}$ & SEC & 190 & $\mathrm{~kg} \mathrm{~mol}^{-1}$ \\
\hline$T_{M}$ & $\operatorname{DSC}\left(\mathrm{N}_{2}, 10^{\circ} \mathrm{C} \mathrm{min}^{-1}\right)$ & 140 & ${ }^{\circ} \mathrm{C}$ \\
\hline$H_{M}$ & $\operatorname{DSC}\left(\mathrm{N}_{2}, 10^{\circ} \mathrm{C} \mathrm{min}^{-1}\right)$ & 74 & $\mathrm{~kJ} \mathrm{~mol}^{-1}$ \\
\hline$T_{C}$ & $\operatorname{DSC}\left(\mathrm{N}_{2}, 10^{\circ} \mathrm{C} \mathrm{min}^{-1}\right)$ & 113 & ${ }^{\circ} \mathrm{C}$ \\
\hline$H_{C}$ & $\operatorname{DSC}\left(\mathrm{N}_{2}, 10^{\circ} \mathrm{C} \mathrm{min}^{-1}\right)$ & 76 & $\mathrm{~kJ} \mathrm{~mol}^{-1}$ \\
\hline isoT & IR (transmission) & 59 & $\%$ \\
\hline$X_{C}$ & $\operatorname{DSC}\left(\mathrm{N}_{2}, 10^{\circ} \mathrm{C} \mathrm{min}^{-1}\right)$ & 50 & $\%$ \\
\hline$L_{C}$ & $\operatorname{DSC}\left(\mathrm{N}_{2}, 10^{\circ} \mathrm{C} \mathrm{min}^{-1}\right)$ & 3 & $\mathrm{~nm}$ \\
\hline
\end{tabular}

TABLE II Main Characteristics of the PP Powder Under Study

$M_{W}=$ weight average molar mass; $T_{M}=$ melting temperature; $H_{M}=$ heat of melting; $T_{C}=$ crystallization temperature; $H_{C}=$ heat of crystallization; isoT = isotacticity; $X_{C}=$ crystallinity ratio; $L_{C}=$ crystalline lamella thickness. 
TABLE III

Operating Conditions in Rotational Molding

\begin{tabular}{ccccc}
\hline $\begin{array}{c}\text { Piece } \\
\text { number }\end{array}$ & $\begin{array}{c}\text { Heating } \\
\text { time } \\
(\mathrm{min})\end{array}$ & $\begin{array}{c}\text { Air-cooling } \\
\text { time (min) }\end{array}$ & $\begin{array}{c}\text { Rotation } \\
\text { rate around } \\
\text { axis 1 (rpm) }\end{array}$ & $\begin{array}{c}\text { Rotation } \\
\text { rate around } \\
\text { axis 2 (rpm) }\end{array}$ \\
\hline 1 & 20 & 20 & 9.6 & 4 \\
2 & 25 & 20 & 9.6 & 4 \\
3 & 30 & 20 & 9.6 & 4 \\
4 & 35 & 20 & 9.6 & 4 \\
5 & 45 & 20 & 9.6 & 4 \\
\hline
\end{tabular}

$$
\mathrm{L}_{\mathrm{C}}=\frac{2 \mathrm{~T}_{\mathrm{M} 0} \sigma}{\rho_{\mathrm{C}} \Delta \mathrm{H}_{\mathrm{M} 0}}\left(\frac{1}{\mathrm{~T}_{\mathrm{M} 0}-\mathrm{T}_{\mathrm{M}}}\right)
$$

with: $T_{\mathrm{M} 0}=459 \mathrm{~K}, \sigma=3.10^{-2} \mathrm{~J} \mathrm{~m}^{-2}, \rho_{\mathrm{C}}=0.946$ and $\Delta H_{\mathrm{M} 0}=209 \mathrm{~J} \mathrm{~g}^{-1} .66$

\section{Processing conditions}

To check the validity of the "thermal" kinetic model, four different spherical PP pieces of thickness $e_{p}=2$ $\mathrm{mm}$ were processed in an aluminummold of thickness $e_{m}=5 \mathrm{~mm}$ and inner diameter $d_{m}=78 \mathrm{~mm}$, with a rotational molding machine STP LAB 40 equipped by an electrical furnace maintained at a constant temperature $T_{f}=300^{\circ} \mathrm{C}$. The corresponding processing conditions are given in Table III. They differ only by the duration of the heating stage. Indeed, all the other parameters, i.e. the duration of the air-cooling stage, the rotation rates around the principal and secondary axes (numbered 1 and 2 respectively), are identical.

During the processing operations, the internal air temperature $T_{a}$ was measured in the center of the mold with a thermocouple. Some thermograms are presented in Figure 6. The various heating times are indicated on the curves. By approximating the heating and cooling stages of these thermograms by a straight-line, it was possible to determine graphically the average heating and cooling rates. From this approach, it was found an absolute value of about $10^{\circ} \mathrm{C} \mathrm{m^{-1 }}$ for both rates.

\section{Thermal aging tests}

To check the validity of the "chemical" kinetic model, now extended to stabilized PP, thick PP

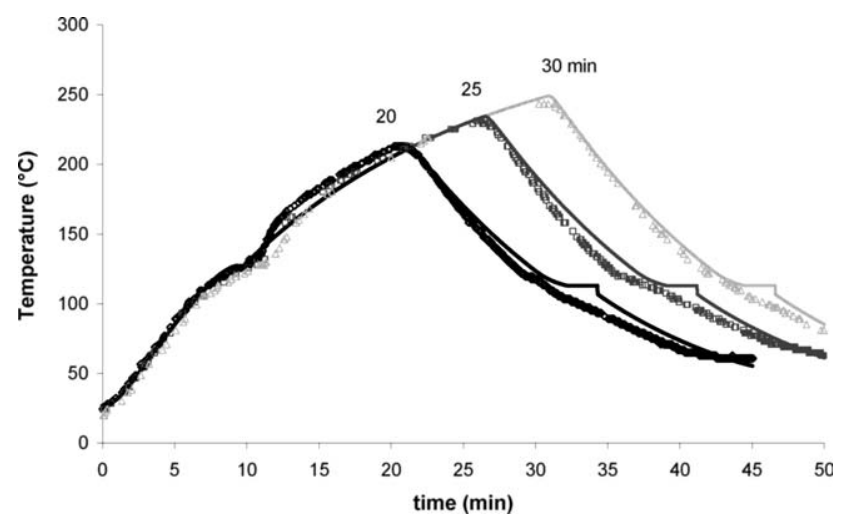

Figure 6 Changes in internal air temperature against processing time: $\mathrm{T}_{\mathrm{a}}(\mathrm{t})$, for some processing conditions under study (Table III). Comparison between theory (curves) and experiment (points). The various heating times are indicated on the curves.

samples (of $4.0 \pm 0.1 \mathrm{~mm}$ thickness) were processed by injection molding and microtome cut into thin slices of $40 \pm 2 \mu \mathrm{m}$ thickness, perpendicularly to sample surfaces. Then, PP slices were aged in atmospheric air in thermal cycle conditions relatively close to those previously described for rotational molding. The different thermal aging conditions are reported in Table IV.

Some PP slices were placed on $\mathrm{KBr}$ plates, heated in air-ventiled ovens and removed, at defined aging times, for FTIR analysis. They were examined by a Brucker IFS 28 IR spectrophotometer, with a minimal resolution of $4 \mathrm{~cm}^{-1}$, in a transmission mode to determine the changes of the ketone absorbance (at $1713-1722 \mathrm{~cm}^{-169-72}$ ) against time of exposure.

The global ketone concentration was determined using the classical Beer-Lambert equation and the respective usual molar absorptivity for ketones:

$$
[\mathrm{P}=\mathrm{O}]=\frac{\mathrm{DO}}{\mathrm{e}_{\mathrm{P}} \varepsilon_{\mathrm{P}=\mathrm{O}}}
$$

where DO is the measured IR absorbance;

$\mathrm{e}_{\mathrm{p}}$ is the sample thickness (in $\mathrm{cm}$ ) and $\varepsilon_{\mathrm{P}=\mathrm{O}}$ is the ketone molar absorptivity taken equal to $200 \mathrm{~L}$ $\mathrm{mol}^{-1} \mathrm{~cm}^{-1}$. $^{73}$

Others PP slices, of about $2 \mathrm{mg}$ initial mass, were placed on the plateau of a Netzsch TG 209 microbalance and submitted to a temperature dynamic

TABLE IV

Thermal Ageing Conditions for Thin Stabilized PP Films

\begin{tabular}{cccccc}
\hline $\begin{array}{c}\text { Film } \\
\text { number }\end{array}$ & $\begin{array}{c}\text { Initial } \\
\text { temperature } \\
\left({ }^{\circ} \mathrm{C}\right)\end{array}$ & $\begin{array}{c}\text { Heating } \\
\text { rate } \\
\left({ }^{\circ} \mathrm{C} \mathrm{min}^{-1}\right)\end{array}$ & $\begin{array}{c}\text { Maximal } \\
\text { temperature } \\
\left({ }^{\circ} \mathrm{C}\right)\end{array}$ & $\begin{array}{c}\text { Cooling } \\
\text { rate } \\
\left({ }^{\circ} \mathrm{C} \min ^{-1}\right)\end{array}$ & $\begin{array}{c}\text { Final } \\
\text { temperature } \\
\left({ }^{\circ} \mathrm{C}\right)\end{array}$ \\
\hline 1 & 170 & 5 & 250 & 5 & 170 \\
2 & 170 & 10 & 250 & 10 & 170 \\
\hline
\end{tabular}


TABLE V

"Material" Parameters (for Solid and Molten polymer, Mold and External and Internal air) Used for Modeling Thermal Transfer Phenomena During Rotational Molding

\begin{tabular}{|c|c|c|c|c|}
\hline "Material" & Parameter & Source (temperature) & Value & Unity \\
\hline \multirow[t]{3}{*}{ Solid PP } & $\rho_{\mathrm{sp}}$ & Technical sheet $\left(25^{\circ} \mathrm{C}\right)$ & 854 & $\mathrm{~kg} \mathrm{~m}^{-3}$ \\
\hline & $k_{\mathrm{sp}}$ & Ref. $43\left(25^{\circ} \mathrm{C}\right)$ & 0.2 & $\mathrm{~W} \mathrm{~m}{ }^{-1} \mathrm{~K}^{-1}$ \\
\hline & $C_{\mathrm{sp}}$ & $\operatorname{DSC}\left(\mathrm{N}_{2}, 10^{\circ} \mathrm{C} \cdot \mathrm{min}^{-1)}\left(25^{\circ} \mathrm{C}\right)\right.$ & 500 & $\mathrm{~J} \mathrm{~kg}^{-1} \mathrm{~K}^{-1}$ \\
\hline \multirow[t]{3}{*}{ Molten PP } & $\rho_{\mathrm{lp}}$ & Equ. $31\left(200^{\circ} \mathrm{C}\right)$ & 832 & $\mathrm{~kg} \mathrm{~m}^{-3}$ \\
\hline & $k_{\mathrm{lp}}$ & Ref. $74\left(150^{\circ} \mathrm{C}\right)$ & 0.15 & $\mathrm{~W} \mathrm{~m}{ }^{-1} \mathrm{~K}^{-1}$ \\
\hline & $C_{l p}$ & $\operatorname{DSC}\left(\mathrm{N}_{2}, 10^{\circ} \mathrm{C} \cdot \mathrm{min}^{-1)}\left(150^{\circ} \mathrm{C}\right)\right.$ & 1000 & $\mathrm{~J} \mathrm{~kg}^{-1} \mathrm{~K}^{-1}$ \\
\hline \multirow[t]{3}{*}{ Aluminum mold } & $\rho_{\mathrm{m}}$ & Ref. 75 & 2700 & $\mathrm{~kg} \mathrm{~m}^{-3}$ \\
\hline & $k_{m}$ & Ref. 76 & 218 & $\mathrm{~W} \mathrm{~m}{ }^{-1} \mathrm{~K}^{-1}$ \\
\hline & $C_{m}$ & Ref. 76 & 950 & $\mathrm{~J} \mathrm{~kg}^{-1} \mathrm{~K}^{-1}$ \\
\hline External air & $h_{\mathrm{ea}}$ & Ref. 42 & 25 & $\mathrm{~W} \mathrm{~m}{ }^{-2} \mathrm{~K}^{-1}$ \\
\hline Internal air & $h_{\mathrm{ia}}$ & Ref. 42 & 5 & $\mathrm{~W} \mathrm{~m} \mathrm{~m}^{-2} \mathrm{~K}^{-1}$ \\
\hline
\end{tabular}

program in atmospheric air. Their mass was recorded continuously versus temperature and time of exposure in a computer.

\section{Piece characterization}

To check the validity of the general degradation model, constituted by the juxtaposing of the "thermal" and "chemical" levels, the four polymer pieces processed by rotational molding were microtome cut into thin slices of $40 \pm 2 \mu \mathrm{m}$ thickness, perpendicularly to the inner piece surface. Then, slice crosssections were examined by FTIR cartography (Brucker IFS 28 IR spectrophotometer) in a transmission mode to determine the spatial distribution (in the piece thickness) of ketone absorbance. The global ketone concentration was determined using the classical Beer-Lambert equation [eq. (35)], as for thermal aging tests.

\section{RESULTS AND DISCUSSION}

\section{Validation of the "thermal" level}

The different "material" parameters appearing in the "thermal" kinetic model [i.e., in eq. (4-14)] were determined before any simulation. Some parameters, in particular temperatures $\left(T_{M}\right.$ and $\left.T_{C}\right)$ and heats $\left(H_{M}\right.$ and $\left.H_{C}\right)$ of polymer phase changes, were determined by DSC at the laboratory. Let's recall that their values are given in Table II.

The density of solid polymer $\left(\rho_{\mathrm{sp}}\right)$ was taken in the technical sheet supplied by ICOPOLYMERS Company. The density liquid polymer $\left(\rho_{\mathrm{lp}}\right)$ was determined from Equ. 31.

All the other parameters, i.e. calorimetric capacities of solid and liquid polymer and aluminummold $\left(C_{\mathrm{sp}}, C_{\mathrm{lp}}\right.$ and $\left.C_{\mathrm{m}}\right)$, thermal conductivities of solid and liquid polymer and aluminummold $\left(k_{\mathrm{sp}}, k_{\mathrm{lp}}\right.$ and $\left.k_{\mathrm{m}}\right)$ and convection coefficients of external and internal air $\left(h_{e a}, h_{i a}\right)$, were compiled from the litera- ture ${ }^{42,43,74-76}$ or measured experimentally. Their values are given in Table $\mathrm{V}$.

Simulations of thermograms recorded during processing in the internal air (in the center of the mold, $\mathrm{z}=\mathrm{L}$ ) are reported in Figure 6 . It can be observed a satisfying agreement between theory and experiment. As an example, a magnification of the first thermogram, obtained after $20 \mathrm{~min}$, is presented in Figure 7. It can be also noted a satisfying modeling of the pseudo-plateau of melting.

Unfortunately, the pseudo-plateau of crystallization is not as well described by the "thermal" kinetic model. To tentatively reduce this gap between theory and experiment, some authors have proposed to simulate this latter by using a more phenomenological model than the enthalpy method, in particular deduced from the crystallization kinetics determined by DSC. ${ }^{77}$ This way of improvement is under investigation at the laboratory.

\section{Validation of the "chemical" level}

The different kinetic parameters appearing in the "chemical" kinetic model [i.e., in eq. (16-32)] were determined before any simulation. Some parameters,

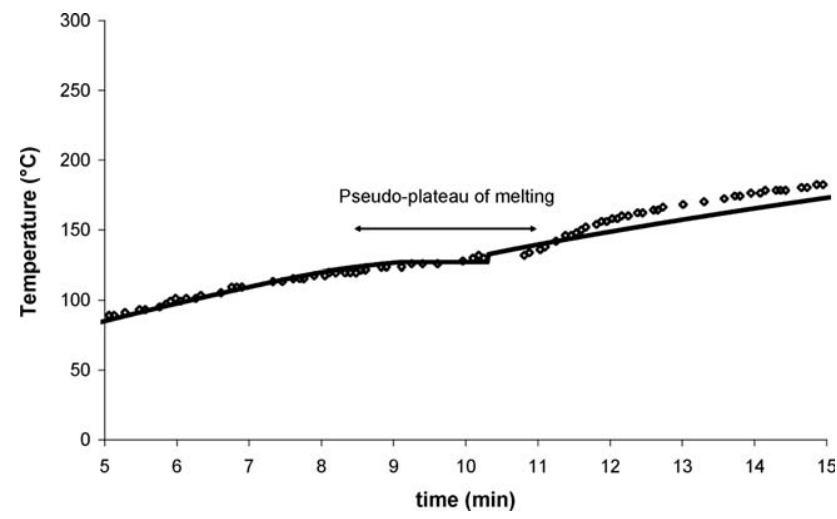

Figure 7 Pseudo-plateau of melting for the first processing condition under study (Table III). Comparison between theory (curves) and experiment (points). 
TABLE VI

Kinetic Parameters Used for Modelling PP Thermal degradation

\begin{tabular}{|c|c|c|c|c|}
\hline Parameter & $E_{\mathrm{i}}\left(\mathrm{kJ} \mathrm{mol}^{-1}\right)$ & $k_{\mathrm{i} 0}$ & (Unity) & Source \\
\hline $\mathrm{k}_{1 \mathrm{u}}$ & 141 & $3.9 \times 10^{12}$ & $\mathrm{~s}^{-1}$ & Ref. 36 \\
\hline $\mathrm{k}_{1 \mathrm{~b}}$ & 82 & $1.5 \times 10^{7}$ & $\mathrm{~L} \mathrm{~mol}^{-1} \mathrm{~s}^{-1}$ & Ref. 36 \\
\hline $\mathrm{k}_{2}$ & 0 & $10^{8}$ & $\mathrm{~L} \mathrm{~mol}^{-1} \mathrm{~s}^{-1}$ & Ref. 78 \\
\hline $\mathrm{k}_{3}$ & 65.5 & $3.0 \times 10^{8}$ & $\mathrm{~L} \mathrm{~mol}^{-1} \mathrm{~s}^{-1}$ & Ref. 79 \\
\hline $\mathrm{k}_{4}$ & 0 & $10^{10}$ & $\mathrm{~L} \mathrm{~mol}^{-1} \mathrm{~s}^{-1}$ & Ref. 36 \\
\hline $\mathrm{k}_{5}$ & 0 & $10^{9}$ & $\mathrm{~L} \mathrm{~mol}^{-1} \mathrm{~s}^{-1}$ & Ref. 36 \\
\hline $\mathrm{k}_{60}$ & 82 & $1.8 \times 10^{17}$ & $\mathrm{~L} \mathrm{~mol}^{-1} \mathrm{~s}^{-1}$ & Ref. 36 \\
\hline $\mathrm{k}_{61}$ & 6.6 & $2.5 \times 10^{7}$ & $\mathrm{~s}^{-1}$ & Ref. 36 \\
\hline $\mathrm{k}_{63}$ & 31.7 & $1.4 \times 10^{11}$ & $\mathrm{~s}^{-1}$ & Ref. 36 \\
\hline $\mathrm{k}_{71}$ & 80 & $1.2 \times 10^{10}$ & $\mathrm{~L} \mathrm{~mol}^{-1} \mathrm{~s}^{-1}$ & This study \\
\hline $\mathrm{k}_{72}$ & 20.5 & $3.7 \times 10^{7}$ & $\mathrm{~L} \mathrm{~mol}^{-1} \mathrm{~s}^{-1}$ & This study \\
\hline$\left[\mathrm{O}_{2}\right]_{\mathrm{S}}$ & 0 & $1.3 \times 10^{-3}$ & $\mathrm{~mol} \mathrm{~L}^{-1}$ & eq. (36) and Ref. 86 \\
\hline $\mathrm{D}_{\mathrm{O}_{2}}$ & 47.7 & $4.6 \times 10^{-3}$ & $\mathrm{~m}^{2} \mathrm{~s}^{-1}$ & eq. (37) and Ref. $80-83$ \\
\hline $\mathrm{D}_{\text {Dec }}$ & 94 & $1.9 \times 10^{3}$ & $\mathrm{~m}^{2} \mathrm{~s}^{-1}$ & eq. (37) and Ref. 84 \\
\hline $\mathrm{D}_{\mathrm{AH}}$ & 100 & 4.6 & $\mathrm{~m}^{2} \mathrm{~s}^{-1}$ & eq. (37) and Ref. 85 \\
\hline$\beta_{\text {Dec }}$ & - & $10^{-5}$ & $\mathrm{~s}^{-1}$ & This study \\
\hline$\beta_{\mathrm{AH}}$ & - & $10^{-5}$ & $\mathrm{~s}^{-1}$ & This study \\
\hline$\gamma_{1}$ & - & $90-99.9$ & $\%$ & Ref. 36 \\
\hline$\gamma_{4}$ & - & 16 & $\%$ & Ref. 36 \\
\hline$\gamma_{5}$ & - & 50 & $\%$ & Ref. 36 \\
\hline $\mathrm{V}$ & - & $84.7-88$ & $\%$ & Ref. 36 \\
\hline
\end{tabular}

$E_{\mathrm{i}}=$ activation energies; $k_{\mathrm{i} 0}=$ preexponential factors.

in particular propagation rate constants $\left(k_{2}\right.$ and $\left.k_{3}\right)$, coefficients of molecular species diffusion $\left(\mathrm{D}_{\mathrm{O}_{2}}, \mathrm{D}_{\mathrm{Dec}}\right.$ and $\left.\mathrm{D}_{\mathrm{AH}}\right)$ and equilibrium oxygen concentration $\left(\left[\mathrm{O}_{2}\right]_{0}\right.$ or $\left.\left[\mathrm{O}_{2}\right]_{\mathrm{S}}\right)$, were determined from a literature compilation. ${ }^{78-86}$ However, transport properties of molecular species into polymers are always given in solid state (i.e. below the melting temperature $\mathrm{T}_{\mathrm{M}}$ ) in the literature. In a first approach, values into molten PP were predicted from values measured into semicrystalline PP above its glass transition temperature, knowing its crystallinity ratio $\mathrm{x}_{\mathrm{C}}$ :

$$
\begin{aligned}
{\left[\mathrm{O}_{2}\right]_{\text {melt }} } & =\frac{\left[\mathrm{O}_{2}\right]_{\text {semi-cryst }}}{1-\mathrm{x}_{\mathrm{C}}} \\
D_{\text {melt }} & =\frac{D_{\text {semi-cryst }}}{1-\mathrm{x}_{\mathrm{C}}}
\end{aligned}
$$

The resulting values are reported in Table VI.

All the other unknown parameters, i.e. other rate constants $\left(k_{1 \mathrm{u}}, k_{1 \mathrm{~b}}, k_{4}, k_{5}, k_{60}, k_{61}, k_{63}, k_{71}\right.$ and $\left.k_{72}\right)$, yields $\left(v, \gamma_{1}, \gamma_{4}\right.$ and $\left.\gamma_{5}\right)$ and coefficients of crossing the polymer/air interface by both types of antioxidants $\left(\beta_{\text {Dec }}\right.$ and $\left.\beta_{\mathrm{AH}}\right)$, were determined using the "chemical" kinetic model as an inverse method. However, because of the high number of kinetics parameters remaining to determine, we adopted the following step-by-step approach:

- First, isothermal oxidation of thin free additive PP films in melt state, in a large temperature range (typically between 170 and $250^{\circ} \mathrm{C}$ ) and in atmospheric air. Simulation of the resulting kinetic curves of ketone build-up and mass changes to determine the vast majority of remaining parameters (i.e., $k_{1 \mathrm{u}}, k_{1 \mathrm{~b}}, k_{4}$, $k_{5}, k_{60}, k_{61}, k_{63}, v, \gamma_{1}, \gamma_{4}$ and $\left.\gamma_{5}\right)$.

- Then, thermal oxidation of thin stabilized PP films in thermal cycle conditions relatively close to processing ones. Simulation of the resulting kinetic curves of ketone build-up and mass changes to determine the parameters related to antioxidants (i.e. $k_{71}, k_{72}, \beta_{\text {Dec }}$ and $\left.\beta_{\mathrm{AH}}\right)$.

The first step of this approach has been performed in a previous communication. ${ }^{36}$ The second step is the objective of the present communication. The values of all these parameters are also given in Table VI.

Values obtained for the stabilization rate constants $k_{71}$ and $k_{72}$ seem quite realistic for different reasons:

- The order of magnitude of pre-exponential factors $\left(10^{7}-10^{10} \mathrm{~L} \mathrm{~mol}^{-1} \mathrm{~s}^{-1}\right)$ corresponds well to that usually reported in the literature for bimolecular reactions ${ }^{87-90}$;

- The activation energy of $k_{71}\left(80 \mathrm{~kJ} \mathrm{~mol}^{-1}\right)$ is logically close to that previously determined for $k_{1 \mathrm{~b}}\left(82 \mathrm{~kJ} \mathrm{~mol}^{-1}\right)$;

- The activation energy of $k_{72}\left(20.5 \mathrm{~kJ} \mathrm{~mol}^{-1}\right)$ is logically lower than that previously reported for $k_{3}\left(65.5 \mathrm{~kJ} \mathrm{~mol}^{-1}\right)$, since hydrogen atoms are largely more labile in Irganox 1010 than in PP substrate. ${ }^{79}$ Moreover, the same 


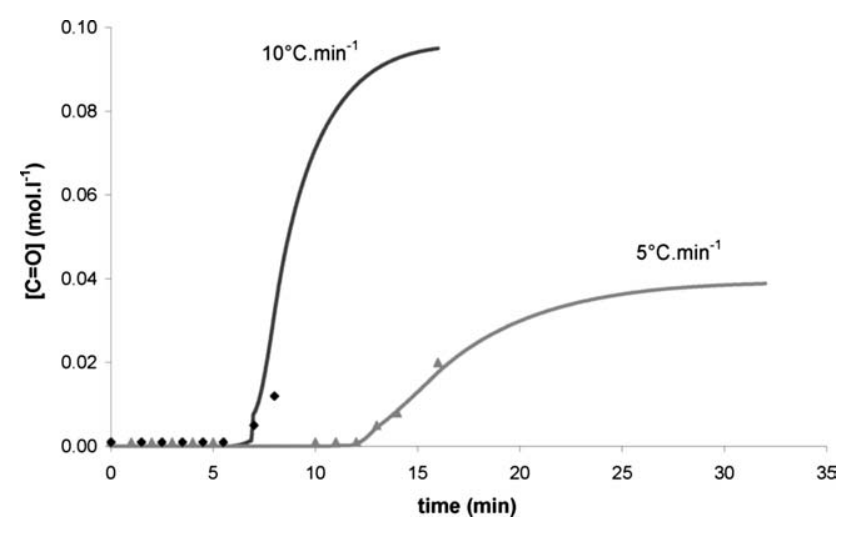

Figure 8 Ketone build-up in thin stabilized PP films for both thermal cycle conditions under study (Table IV). Comparison between theory (curves) and experiment (points). The various heating/cooling rates are indicated on the curves.

value has been determined by Gol'dberg et al. for the same antioxidant, but in another polyolefin matrix: PE. ${ }^{91}$

Simulations of the kinetic curves of ketone buildup and mass changes of thin stabilized PP films (of $\approx 40 \mu \mathrm{m}$ thickness) submitted to thermal cycle conditions relatively close to processing ones (see Table IV) are reported in Figures 8 and 9. In both cases, it can be observed a satisfying agreement between theory and experiment.

These results call for the following comments:

i. The duration of the induction period, i.e., the time required to consume all the antioxidant molecules, is a decreasing function of the heating rate. It is approximately the same for the kinetics curves of ketone build-up and mass changes. It is about $12 \mathrm{~min}$ for a heating rate of $5^{\circ} \mathrm{C} \mathrm{min} \mathrm{min}^{-1}$, and $6 \mathrm{~min}$ for a heating rate of $10^{\circ} \mathrm{C} \mathrm{min}^{-1}$. Moreover, whatever the heating rate, we note that films mass loss at $T=$ $235^{\circ} \mathrm{C}$ is around $5 \%$. This would be the interesting features of the degradation of PP during its processing by rotational molding. In others words, in the case of thin samples (of $\approx$ $40 \mu \mathrm{m}$ thickness), thermal oxidation would take place during the heating stage of the processing operation. This important characteristic is satisfyingly predicted by the "chemi$\mathrm{cal}^{\prime \prime}$ kinetic model.

ii. The duration of the induction period is thus largely lower than the time for a whole processing operation by rotational molding ( $\approx 35-45 \mathrm{~min}$, depending on the heating time, see Fig. 6). It is expected that the synergistic blend of antioxidants under study is not very efficient in real rotational molding conditions. iii. Once all the antioxidant molecules consumed, thermal oxidation leads to catastrophic mass losses. As an example, when the temperature reaches $250^{\circ} \mathrm{C}$, more than $80 \%$ of the initial mass of PP films (i.e., about $1.7 \mathrm{mg}$ of the initial $2.0 \mathrm{mg}$ ) is volatilized. This result is not surprising since we have shown, in a previous publication, ${ }^{36}$ that PP thermal oxidation at high temperature in melt state generates a relatively efficient predominant chain scission process (of corresponding yield $\gamma_{1}>90 \%$ between 190 and $250^{\circ} \mathrm{C}$ ) leading to a high amount of volatile compounds, in particular acetone (of corresponding yield $v>84 \%$ between 190 and $250^{\circ} \mathrm{C}$ ). In fact, acetone formation can be described as a "zip process" (i.e., a depolymerisation), in which the rapid rearrangement, by $\beta$ scission, of each alkoxy radical $\left(\mathrm{PO}^{\bullet}\right)$ leads to the formation of an acetone molecule.

\section{Prediction of thermal degradation in processing conditions}

Once fully validated, the "thermal" and "chemical" levels were juxtaposed to constitute a general kinetic model aimed to predict PP thermal degradation in real rotational molding conditions. Examination by FTIR cartography of some PP pieces under study (see Table III) reveals that thermal oxidation is restricted to superficial layers at the inner piece surface. Simulations of the spatial distribution (in the piece thickness) of ketone concentrations are reported in Figure 10. It can be observed a satisfying agreement between theory and experiment.

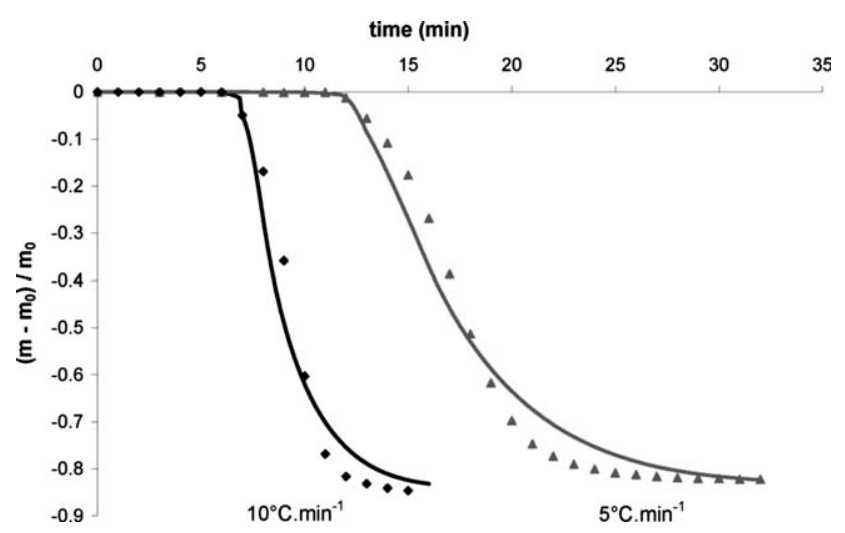

Figure 9 Mass changes of thin stabilized PP films for both thermal cycle conditions under study (Table IV). Comparison between theory (curves) and experiment (points). The various heating/cooling rates are indicated on the curves. 


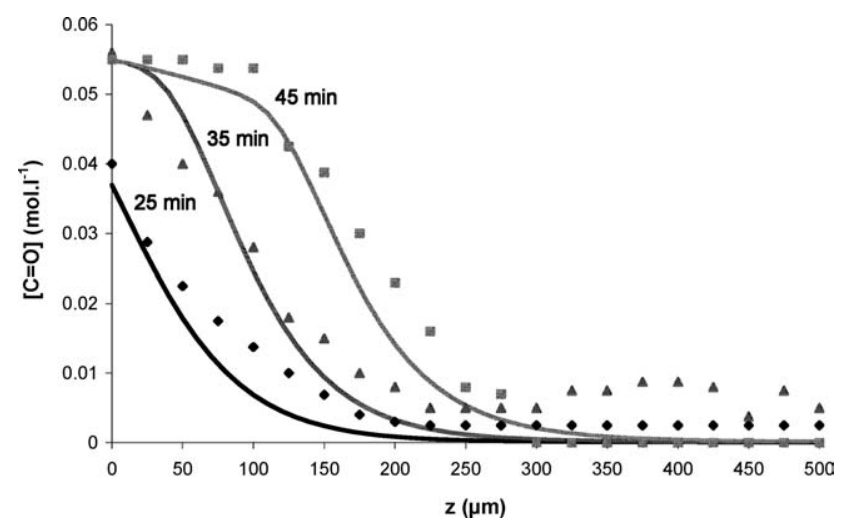

Figure 10 Spatial distribution of ketone concentration at the inner piece surface for some processing conditions under study (Table III). Comparison between theory (curves) and experiment (points). The various heating times are indicated on the curves.

These results call for the following comments:

i. Thermal oxidation starts later and proceeds slower at the inner surface of rotational molded pieces than in thin films aged in thermal cycle conditions close to processing ones (i.e. with heating and cooling rates of $10^{\circ} \mathrm{C} \mathrm{min}{ }^{-1}$ ). Indeed, the duration of the induction period is between 20 and $25 \mathrm{~min}$ for rotational molded piece, whereas it is about $7 \mathrm{~min}$ for films. Moreover, after $25 \mathrm{~min}$, ketone concentration is about $4 \times$ $10^{-2} \mathrm{~mol} \mathrm{~L}^{-1}$ at the inner piece surface, whereas it is about $10^{-1} \mathrm{~mol} \mathrm{~L}^{-1}$ in films. This result is not surprising since it is well known that in thick polymers pieces (typically of few mm thickness), antioxidants migrate from the core towards the piece surfaces to delay and slow down thermal oxidation. Such a phenomenon is named a "reservoir effect." This important characteristic is also satisfyingly predicted by the general kinetic model.

ii. The thickness of oxidized layer TOL is an increasing function of the heating time. Indeed, there is no detection of oxidation products formation at the inner piece surface during the first $20 \mathrm{~min}$ of heating at $T_{f}=300^{\circ} \mathrm{C}$. Then, TOL reaches a value of about $175 \mu \mathrm{m}$ after $25 \mathrm{~min}$, $225 \mu \mathrm{m}$ after $35 \mathrm{~min}$, and $275 \mu \mathrm{m}$ after $45 \mathrm{~min}$. These values are noticeably higher than those usually determined for PP thermal aging in solid state. As an example, Gutierrez et al. reported a value of about $17 \mu \mathrm{m}$ in atmospheric air at $100^{\circ} \mathrm{C}^{92}$ This result is somewhat surprising for the following reasons:

- As a general rule, in a given polymer physical state, TOL is a decreasing function of the temperature $^{93}$;
- A so high value of TOL cannot be totally explained by the sudden increase of the coefficient of oxygen diffusion $\mathrm{D}_{\mathrm{O}_{2}}$ at the solid/ liquid transition. Indeed, application of Equ. 37 gives:

$\frac{\mathrm{D}_{\mathrm{O}_{2}, \text { melt }}}{\mathrm{D}_{\mathrm{O}_{2}, \text { semi-cryst }}}=\frac{1}{1-\mathrm{x}_{\mathrm{C}}} \approx 2$ for a crystallinity ratio close to $50 \%$.

At this stage, it is necessary to recall that the value of TOL can be estimated by a relatively simple scale law ${ }^{93}$ :

$$
\mathrm{TOL}=\left(\frac{\mathrm{D}_{\mathrm{O}_{2}}}{\mathrm{~K}}\right)^{1 / 2}
$$

where $K$ is a pseudo rate constant of the firstorder.

Application of this equation gives:

$$
\frac{\mathrm{TOL}_{\text {melt }}}{\mathrm{TOL}_{\text {semi-cryst }}}=\left(\frac{\mathrm{D}_{\mathrm{O}_{2}, \text { melt }}}{\mathrm{D}_{\mathrm{O}_{2}, \text { semi-cryst }}}\right)^{1 / 2}=2^{1 / 2} \approx 1.4
$$

Thus, an increase of $\mathrm{D}_{\mathrm{O}_{2}}$ (at the solid/liquid transition) with a factor 2 leads to only an increase of TOL with a factor 1.4.

iii) This result can be tentatively explained as follows. At high temperature, in melt state, thermal oxidation leads to a rapid substrate depletion at the inner piece surface (Fig. 11). There is formation of a "dead" superficial layer, in which oxidation rate vanishes. As a result, all the oxygen molecules can freely diffuses toward "active" sublayers (Fig. 12), which leads to a moving of the oxidation front toward deeper layers (Fig. 10).

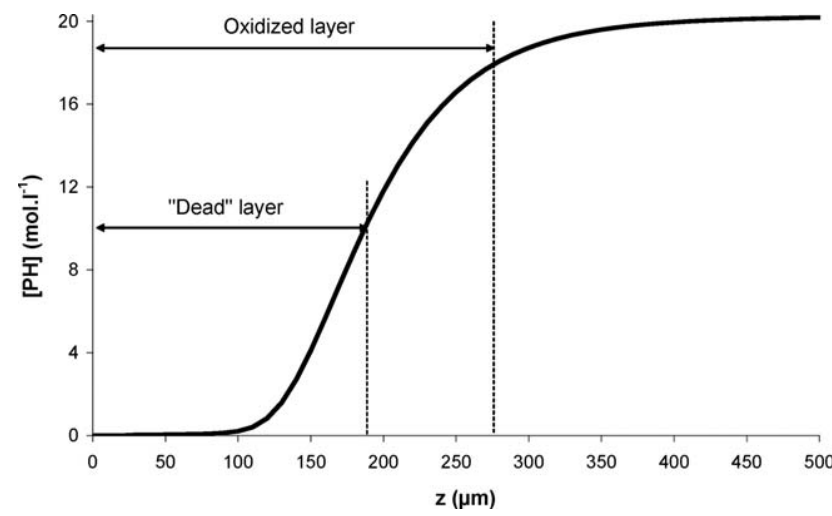

Figure 11 Theoretical spatial distribution of substrate concentration at the inner piece surface for the last processing condition under study (Table III). The "dead" superficial layer is arbitrarily defined as the zone in which the substrate concentration is less than half its initial value. 


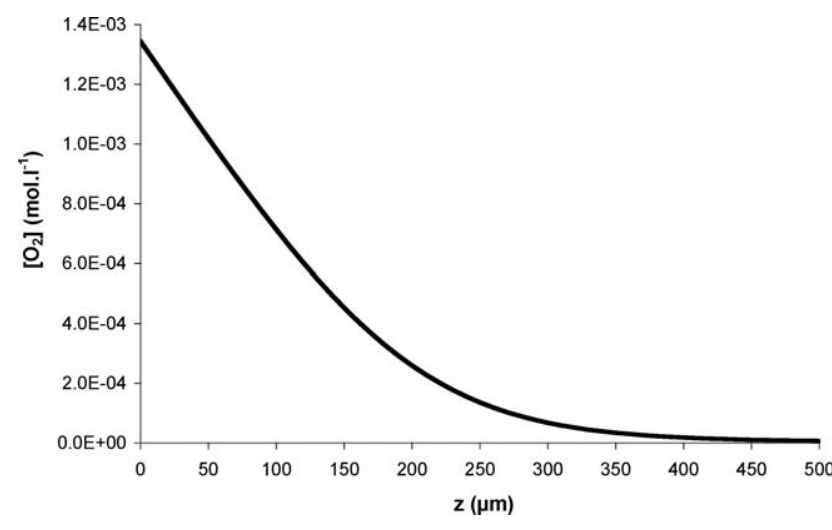

Figure 12 Theoretical spatial distribution of oxygen concentration at the inner piece surface for the last processing condition under study (Table III).

\section{CONCLUSIONS}

A general kinetic model has been elaborated for the simulation of PP thermal degradation at high temperature in melt state (typically between 170 and $250^{\circ} \mathrm{C}$ ). This model is composed of two distinct levels:

- A "thermal" level predicting the temperature gradients developed in the polymer piece during a processing operation;

- And a "chemical" level predicting the local conversion ratio of oxidation process and its spatial distribution in the polymer piece.

The validity of this model has been successfully checked in real rotational molding conditions. Moreover, it allows to explain some important characteristics of PP thermal degradation at the inner piece surface, in particular:

- An high amount of volatile compounds (essentially acetone) responsible for strong mass losses;

- A rapid substrate depletion responsible for an increase of oxygen penetration into deeper layers and thus, the development of an high thickness (of few hundred $\mu \mathrm{m}$ ) of oxidized layer after $25 \mathrm{~min}$ of heating at a furnace temperature of $300^{\circ} \mathrm{C}$.

This model can be now used for the determination of some important boundaries of processing window of rotational molding PP grades, such as: the thermal stability ceiling and the ductile/brittle transition.

\section{References}

1. Crawford, R. J. Rotational Moulding of Plastic, 2nd ed; Research Studies Press LTD: New York, 1996; Chapter 1.

2. Tcharkhtchi, A. Rotomoulage des pièces en matière thermoplastique; Techniques de l'Ingénieur: Paris, 2004.
3. Crawford, R. J.; Scott, J. A. Plast Rubber Proc Appl 1985, 5, 23.

4. Tcharkhtchi, A.; Barcelo, P.; Mazabraud, P.; Jousse, F.; Kearns, M. Adv Eng Mater 2002, 7, 475.

5. Spence, A. G.; Crawford, R. J. Polym Eng Sci 1996, 36, 993.

6. Gogos, G. Proc SPE ANTEC 1999, 45, 1433.

7. Kontopoulou, M.; Vlachopoulos, J. Polym Eng Sci 2001, 41, 155.

8. Hu, X.; Bellehumeur, C. T. J Appl Polym Sci 2006, 102, 5903.

9. Mounif, E.; Bellenger, V.; Tcharkhtchi, A. J Appl Polym Sci 2007, 108, 2908.

10. Crawford, R. J.; Nugent, P. J. Plastics, Rubber Compos Proc Appl 1992, 17, 28.

11. Asgarpour, M. Ph.D. thesis, Arts et Métiers ParisTech, Paris, France.

12. Hafsaoui, S. L. PhD thesis, Arts et Métiers ParisTech, Paris, France.

13. Waigaonkar, S.; Babu, B. J. C. Rotoworld 2008, 4, 72.

14. Crawford, R. J.; Gibson, S. Rational Moulding, the basics for designers. Rotation 2000 (July/August), p. 36.

15. Liu, S. J.; Fu, K. H. Polym Test 2008, 27, 209.

16. Tcharkhtchi, A.; Verdu, J. Adv Eng Mater 2004, 6, 983.

17. Colin, X.; Verdu, J. C R Académie s Sci Chem 2006, 9, 1380.

18. Compilation from the literature. See for instance, Jipa, S.; Setnescu, R.; Setnescu, T.; Zaharescu, T.; Miller, V. B.; Naiman, M. B.; Shlyapnikov, Y.uA.; Hawkins, W. L.; Matreyek, W.; Winslow, F. H. Polym Degrad Stab 2000, 68, 159.

19. Colin, X.; Fayolle, B.; Audouin, L.; Verdu, J. Polym Degrad Stab 2003, 80, 67.

20. Fayolle, B.; Richaud, E.; Colin, X.; Verdu, J. J Mater Sci 2008, 43, 6999.

21. Boss, C. R.; Chien, J. C. W. J Polym Science: Part A: Polym Chem 1966, 1, 1543.

22. Billingham, N. C.; Calvert, P. D. In Developments in Polymer Stabilizations;s Scott, G., Ed; Applied Science Publishers Ltd: London, 1980; p 139.

23. Gillen, K. T.; Wise, J.; Clough, R. L. Polym Degrad Stab 1995, 47, 149 .

24. Commereuc, S.; Vaillant, D.; Philippart, J. L.; Lacoste, J.; Lemaire, J.; Carlsson, D. J. Polym Degrad Stab 1997, 57, 175.

25. Achimsky, L.; Audouin, L.; Verdu, J.; Rychly, J.; MatisovaRychla, L. Polym Degrad Stab 1997, 58, 283.

26. Rincon-Rubio, L.; Fayolle, B.; Audouin, L.; Verdu, J. Polym Degadation Stab 2001, 74, 177.

27. Richaud, E.; Farcas, F.; Bartoloméo, P.; Fayolle, B.; Audouin, L.; Verdu, J. Polym Degrad Stab 2006, 91, 398.

28. Howard, J. A.; Ingold, K. U. Can J Chem 1967, 45, 793.

29. Cramez, M. C.; Oliveira, M. J.; Crawford, R. J. Polym Degrad Stab 2002, 75, 321.

30. Ciolacu, C. F. L.; Choudhury, N. R.; Dutta, N. K. Polym Degrad Stab 2006, 91, 875.

31. Oliveira, M. J.; Botelho, G. Polym Degrad Stab 2008, 93, 139.

32. Xu, X.; Ding, Y.; Qian, Z.; Wang, F.; Wen, B.; Zhou, H.; Zhang, S.; Yang, M. Polym Degrad Stab 2009, 94, 113.

33. Xiang, Q.; Xanthos, M.; Miltra, S.; Patel, S. H.; Guo, J. Polym Degrad Stab 2002, 77, 93.

34. Dintcheva, N. T.; La Mantia, F. P.; Scaffaro, R.; Paci, M.; Acierno, D.; Camino, G. Polym Degrad Stab 2002, 75, 459.

35. Awaja, F.; Pavel, D. Eur Polym J 2005, 41, 1453.

36. Sarrabi, S.; Colin, X.; Tcharkhtchi, A. J Appl Polym Sci 2008, 110, 2030.

37. Sarrabi, S.; Colin, X.; Tcharkhtchi, A.; Heninger, M.; Leprovost, J.; Mestdagh, H. Anal Chem 2009, 81, 6013.

38. Barabas, K.; Iring, M.; Laszlo-Hedvig, S.; Kelen, T.; Tudos, F. Eur Polym J 1977, 14, 405.

39. Kiryushkin, S. G.; Mar'in, A. P.; Shlyapnikov, Y. A. Polym Sci USSR 1980, 22, 1570.

40. Sun, D. W.; Crawford, R. J. Plastic, Rubber Compos Proc Appl 1993, 47, 19. 
41. Crawford, R. J.; Nugent, P. J. Plastics, Rubber Compos Proc Appl 1989, 11, 107.

42. Gogos, G.; Olson, L. G.; Liu, X.; Pasham, V. R. Polym Eng Sci 1998, 38, 1387.

43. Gogos, G.; Olson, L. G.; Liu, X. Polym Eng Sci 1999, 39, 617.

44. Pérot, E. Ph.D. thesis, INSA, Lyon, France, 2006. Available at: http://docinsa.insa-lyon.fr/these/pont.php?id=perot.

45. Zhou, Y.; Fernandez-Pello, A. C. Combust Theory Modell 2000, 4, 477.

46. Tcharkhtchi, A.; Pérot, E.; Chinesta, F. Int Polym Process 2004, 19, 296.

47. Reich, L.; Stivala, S. S. Autooxidation of Hydrocarbons and Polyolefins; Marcel Dekker Inc.: New-York, 1969; pp 141-151.

48. Shelton, R. J. In Stabilization against thermal oxidation, in Polymer Stabilization, Hawkins, W. L., Ed. Wiley-Interscience: New-York, 1971; pp 67-84.

49. Kamiya, Y.; Niki, E. In Oxidative degradation, in Aspects of Degradation and Stabilization of Polymers, Jellinek, H. H. G., Ed. Elsevier Scientific Publishing Company: Amsterdam, 1978; Chapter 3, pp 99-105.

50. Zweifel, H. Plastics Additives Handbook; 5th Ed; Hanser Publishers: Munich, 2001; p 10.

51. Bordwell, F. G.; Zhang, X. M. A. N. J Phys Org Chem 1995, 8, 529.

52. Mulder, P.; Saastad, O. W.; Griller, D. J Am Chem Soc 1988, 110, 4090.

53. Zhu, Q.; Zhang, X. M.; Fry, A. J. Polym Degrad Stab 1997, 57, 43.

54. Denisov, E. T. Polym Degrad Stab 1995, 49, 71.

55. Pospisil, J. Polym Degrad Stab 1993, 40, 217.

56. Pospisil, J. Polym Degrad Stab 1993, 39, 103.

57. Ingold, K. U. Chem Rev 1961, 61, 563.

58. Reich, L.; Stivala, S. S. Autooxidation of Hydrocarbons and Polyolefins; Marcel Dekker Inc.: New-York, 1969; p 220.

59. Shelton, R. J. In Stabilization against Thermal Oxidation, in Polymer Stabilization, Hawkins, W. L., Ed. Wiley-Interscience: New-York, 1971; p 107.

60. Hawkins, W. L.; Worthington, M. A. J Polym Science: Part A: Polym Chem 1963, 1, 3489.

61. Pospisil, J.; Nespurek, S. Handbook of Polymer Degradation, 2nd ed.; Halim Hamid, S., Ed.; Marcel Dekker: New-York, 2000; Chapter 6, p 259.

62. Verdu, J.; Rychly, J.; Audouin, L. Polym Degrad Stab 2003, 79, 503.

63. Coquillat, M.; Verdu, J.; Colin, X.; Audouin, L.; Neviere, R. Polym Degrad Stab 2007, 92, 1334.

64. Hairer, E.; Wanner, G. Solving Ordinary Differential Equation. II-Stiff and Differential-Algebraic Problems; Springer-Verlag: Berlin, 1991; p 5.

65. Picard, C. Solutions de Non-Electrolytes, Thermochimie; De Boeck University: 1996; p 177.

66. Van Krevelen, D. W.; Hoftyzer, P. J. Calorimetric Properties, in Properties of Polymers. Their Estimation and Correlation with Chemical Structure; 2nd ed; Elsevier Scientific Publishing Company: Amsterdam, 1976; Chapter 5, pp 81-97.
67. Heinen, W. J Polym Sci 1959, 38, 545.

68. Mathur, A. B.; Mathur, G. N. Polymer 1982, 23, 54.

69. Teissèdre, G.; Pilichowski, J. F.; Lacoste, J. Polym Degrad Stab $1995,45,145$.

70. George, G. A.; Celina, M.; Vassallo, A. M.; Cole-Clarke, P. A. Polym Degrad Stab 1995, 48, 199.

71. Adams, J. H. J Polym Science: Part A-1 1970, 8, 1077.

72. Lacoste, J.; Vaillant, D.; Carlsson, D. J. J Polym Science: Part A: Polym Chem 1993, 31, 715.

73. Heacok, J. J Appl Polym Sci 1963, 7, 2319.

74. Carvalho, G. D.; Frollini, E.; Dos Santos, W. N. J Appl Polym Sci 1996, 62, 2281.

75. Bouralis, J.; Maeder, G. Elaboration, Structure, Propriétés et Normalisation, Précis de métallurgie, AFNOR: Paris, 1997.

76. Facy, G.; Pompidou, M. Méthodologie, Production et Normalisation, Précis de fonderie, AFNOR: Paris, 1992.

77. Greco, A.; Maffezzoli, A. Adv Polym Technol 2003, 22, 271.

78. Kamiya, Y.; Niki, E. Oxidative degradation, in Aspects of Degradation and Stabilization of Polymers, Jellinek, H. H. G., Ed. Elsevier Scientific Publishing Company: Amsterdam, 1978; Chapter 3, p 86.

79. Korcek, S.; Chenier, J. H. B.; Howard, J. A.; Ingold, K. U. Can J Chem 1972, 50, 2285.

80. Compilation from the literature. See for instance: Stannet, V. Diffusion in polymers, J. Crank and G.S. Park ed., Academic Press, New-York 1968, p. 41.

81. Kiryushkin, S. G.; Gromov, B. A. Vysokomolekulyarnye Soedin 1972, A14, 1715.

82. Kiryushkin, S. G.; Filipenko, V. P.; Gontkovskaya, V. T. Karbonchain Polymers, Nauka, Moscow 1971, p. 182.

83. Felder, R. M.; Spence, R. D.; Ferrell, J. K. J Chem Eng Data 1975, 20, 235.

84. Ferrara, G.; Bertoldo, M.; Scoponi, M.; Ciardelli, F. Polym Degrad Stab 2001, 73, 411.

85. Reynier, A.; Dole, P.; Humbel, S.; Feigenbaum, A. J Appl Polym Sci 2001, 82, 2422.

86. Van Krevelen, D. W.; Hoftyzer, P. J. Permeation of Polymers, in Properties of Polymers. Their Estimation and Correlation with Chemical Structure; 2nd ed; Elsevier Scientific Publishing Company: Amsterdam, 1976; p 406.

87. Colin, X.; Audouin, L.; Verdu, J. Polym Degrad Stab 2004, 86, 309.

88. Colin, X.; Audouin, L.; Verdu, J. Polym Degrad Stab 2007, 92, 886.

89. Khelidj, N.; Colin, X.; Audouin, L.; Verdu, J.; Monchy-Leroy, C.; Prunier, V. Polym Degrad Stab 2006, 91, 1598.

90. Coquillat, M. Ph.D. thesis, ENSAM, Paris, 2007; p 123.

91. Gol'dberg, V. M.; Vidovskaya, L. A.; Zaikov, G. E. Polym Degrad Stab 1988, 20, 113.

92. Gutierrez, G.; Fayolle, B.; Regnier, G. Diffusion limited oxidation in polyolefin nanocomposites, 28th Polymer Degradation Discussion Group Meeting, Sestri Levante, Italy, 6th-10th September 2009.

93. Audouin, L.; Langlois, V.; Verdu, J.; De Bruijn, J. C. M. J Mater Sci 1994, 29, 569. 